Portland State University

PDXScholar

Summer 11-13-2012

\title{
Crafting a Space: A Feminist Analysis of the Relationship Between Women, Craft, Business and Technology on Etsy.com
}

Elizabeth Gillette Offensend

Portland State University

Follow this and additional works at: https://pdxscholar.library.pdx.edu/open_access_etds

Part of the Art and Design Commons, E-Commerce Commons, and the Feminist, Gender, and Sexuality Studies Commons

Let us know how access to this document benefits you.

\section{Recommended Citation}

Offensend, Elizabeth Gillette, "Crafting a Space: A Feminist Analysis of the Relationship Between Women, Craft, Business and Technology on Etsy.com" (2012). Dissertations and Theses. Paper 892.

https://doi.org/10.15760/etd.892

This Thesis is brought to you for free and open access. It has been accepted for inclusion in Dissertations and Theses by an authorized administrator of PDXScholar. Please contact us if we can make this document more accessible: pdxscholar@pdx.edu. 
Crafting a Space: A Feminist Analysis of the Relationship

Between Women, Craft, Business and Technology on Etsy.com

by

Elizabeth Gillette Offensend

A thesis submitted in partial fulfillment of the requirements for the degree of

\author{
Master of Science \\ in \\ Communication
}

\begin{abstract}
Thesis Committee:
Priya Kapoor, Chair

Charlotte Schell

Susan Poulsen
\end{abstract}

Portland State University

2012 
(C) 2012 Elizabeth Gillette Offensend 


\begin{abstract}
In recent years, craft fairs, shows and markets where crafters sell their handmade goods such as pottery, jewelry, handmade clothes and needlework have grown in popularity across the United States. A common intent among individuals in this community echo political statements made by the turn of the century Arts and Crafts movement, while there are political aspects of the community that can also be seen as an extension of the third wave feminist do-it-yourself (DIY) ethic of the late 1990s. This newly enlarged community of crafters that congregates in person also has a strong online presence. Etsy.com plays a large role in this community.

The introduction of websites such as Etsy.com to the communities they serve has widespread impacts. The aim of this study is to analyze how Etsy.com impacts the lives of women who use the website to earn income. Following ethnographic traditions, the researcher interviewed five community members. The focus was on thick description of the DIY community and thematization of interview narratives. To meet participant observation criteria, the researcher also volunteered at the Independent Publishing Resource Center (IPRC) in Portland, Oregon for 4 months. Additionally, the researcher conducted a textual analysis of blogs, websites, artwork, and other sources of data collected from the online hand crafting community.

The study presents and discusses the themes that emerged from the data, including women's work, feminism and technology, the crafters' political statements, the crafters as owners of legitimate businesses, and Etsy.com's impact on local economy. The results paint a picture of the community (both on and offline) and how Etsy.com
\end{abstract}


helps to shape this. The researcher then discusses how to assess the impacts tools such as community websites will have on the communities they serve. 


\section{Acknowledgments}

Thank you to RC, AF, AG, NG and VG for your time, participation and stories. Thank you to Dr. Priya Kapoor, Dr. Susan Poulsen and Dr. Char Schell for your patience, knowledge and guidance. Thank you to Ms. Emily Curry for camaraderie and encouragement. I am grateful to my family for their understanding and open mindedness, and to Ashley for ongoing support. 
Table of Contents

Abstract.........................................................................

Acknowledgments................................................................

Chapter I. Introduction.....................................................1

Research rationale

Research problematic

Review of literature and theoretical framework

Chapter II.

Methodology.

Methodology: Ethnography

Chapter III. Findings...........................................................

Presentation and analysis of data

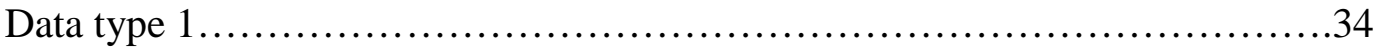

Participant profiles

Online sources from the community

The Etsy.com community

Community saturation

Dealing with conflict

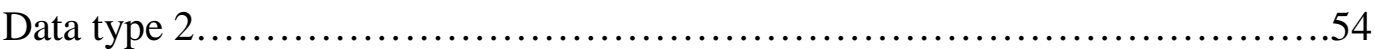

Women's work

Feminism and technology

Making a political statement

Legitimate business

Local economy

Chapter IV. Discussion and Conclusion.

Discussion

Etsy.com: recent developments

Implications for future research

Limitations

Concluding remarks

Works Cited.....

.90

Supplementary Materials: Images of blogs and industry websites referenced in research...................................................... Supplementary File 
Chapter I: Introduction

Several years ago (in 2006), while working for an interactive marketing firm, I frequently fielded inquiries from entrepreneurial individuals looking to begin an online business. Many of these people had wonderfully creative and inventive ideas for businesses that required intricate websites, but were disappointed to discover the cost involved in creating a complex website from scratch. The individuals were unaware of the enormous costs involved in programming, maintaining and hosting websites owned by large organizations, such as Ebay.com, MySpace.com and Amazon.com, and I could hear the frustration in their voices as we discussed pricing. Other individuals I spoke with attempted lower cost options to make their vision a reality, but had been taken advantage of or paid to have a website made that was never completed or was of very low quality. These barriers to going “online” seemed insurmountable to many, and I am certain many plausible and creative endeavors were left by the wayside due to the cost of starting an online business.

Around the same time, I noticed an increase in the popularity of hand crafting. A local knitting shop popped up around the corner from my apartment, and several clients at work referred me to blogs they liked that they wanted use as inspiration for their websites. This was my introduction to what I refer to as crafting blogs (sewing, knitting, cooking, homemaking, etc.). I discovered a huge online community of crafters, and it seemed crafting classes and craft fairs were everywhere I looked. I discovered Etsy.com (an online marketplace for handmade goods) around this time, and I found a solution to propose for those small craft business owners who wanted to sell handmade goods on their website, but were unable to afford to build their own. For a low cost, Etsy.com 
allows users to create their own online shop to sell their handmade items. The following research stems from my inquiry into how the development of websites like Etsy.com affects individuals, their livelihoods and communities, and social movements such as the burgeoning handcrafting phenomenon.

\section{Research Rationale}

In recent years, craft fairs, shows and markets where crafters sell their handmade goods such as pottery, jewelry, handmade clothes and needlework have popped up across cities and towns across the United States (Walker, 2007). Elements of this crafting community and its movement echo the political statements made by the turn of the century Arts and Crafts movement in that the creation of items by hand is a statement against industrialization and consumerism of mass produced goods. There are political aspects of this recent movement that can also be seen as an extension of the third wave feminist do-it-yourself (DIY) ethic of the late 1990s (Minahan and Wolfram Cox, 2007). This newly enlarged community of crafters that congregates in person also has a strong online presence. This can be seen today in the plentiful crafting blogs and forums and on websites such as getcrafty.com, crafter.org, ravelry.com and Etsy.com. These community specific websites address the phenomenon described earlier of individuals looking to create a website where they can sell items and interact with others, without the overhead cost of developing their own individual website.

Etsy.com in particular can be seen as one of the most recent steps in the online progression of this handcrafting community. At the time of this research, it is a relatively new company and website (about three years old at the beginning of 2009). It allows 
crafters to create online shops to sell their wares, and features forums, chat rooms and online resources that create space for this community to congregate and share information virtually. This website has grown immensely in popularity since its inception. A March 2008 interview with Etsy.com creator Rob Kalin on The Martha Stewart Show revealed that the website was approaching one million members.

The return to handcrafting and the incorporation of online tools in the movement has strengthened this creative outlet for members of the community and supports a means to make a political statement while shunning corporate brand culture and mass production. However, the impact of online tools, such as Etsy.com, on the communities and people they serve remains unstudied. The purpose of this study is to analyze handcrafters' use of and interactions with Etsy.com.

\section{Research Problematic}

The return to creating traditional handcrafts is a symbol of choice and reclamation by third wave feminists. The use of online tools such as blogs and e-commerce websites, and Etsy.com in particular, has created a space for this movement to grow and strengthen its community. I am curious how feminist handcrafters use community websites such as Etsy.com. The purpose of this study is to understand how women who are a part of this community use these tools.

Review of Literature

Craft Community Characteristics and Popularity 
As mentioned above, this growth in popularity of handcrafted items can be seen in the past decade in multiple ways, but first it is important to describe the characteristics of what defines and who partakes in this community. The members of this community may handcraft many types of items, from metal work jewelry, to pottery, to woven and knitted house wares and clothing items. The knitting community in particular has a notably strong online presence, using blogs and other tools to post patterns, ask and answer questions, and share techniques. Knitting is just one of the smaller communities within the craft culture, and can be seen as affiliated with and defined by one of the most visible contributors to the growth of the movement, which was the 2003 publication of Debbie Stoller's book Stitch 'n Bitch. The book discusses the basics of teaching oneself to knit, and it quickly spawned groups of women internationally to gather both in person and virtually via the Internet under the name "Stitch 'n Bitch.” These groups get together to knit and "bitch," or socialize, and are found in universities, within corporations, in pubs, coffee houses and private homes throughout Europe, the USA and Oceania (Minahan and Wolfram Cox). Stoller, also publisher of the feminist magazine BUST, incorporated the same trendy and edgy tone and graphics from the magazine into the book. The audience of the magazine and book generally overlap and is described on the BUST website as “cutting-edge young women.” The Craft Yarn Council of America found in a 2005 study that young women, ages 25 to 34, are “the secret spark that's fueling knitting and crochet yarn sales across the country.” The National Needle Arts Association has also noted this recent growth in the popularity of knitting, commenting on its website that the general craft market and the needle arts industry specifically have shown major increases starting in 2001. This recent growth in the popularity of knitting, crocheting and other 
needlework among young women is surprising as this may typically be considered a hobby that belongs to elderly women. But, as the motto of Sublime Stitching, a trendy boutique supplier of embroidery supplies to this community, states, “This ain't your gramma’s embroidery!”

The media has also recently picked up on the growing trend of young women's interests in knitting and crafting in general, with the New York Times and other newspapers publishing profile articles on young women, typically in their mid 20s to mid 30s, who support themselves by making and selling handcrafted clothes, jewelry, hats, bags and other items. A Portland, Oregon alternative newspaper claims that "if you haven't been paying attention, you may have missed the craft phenomenon that has overtaken Portland in the past decade,” and goes on to profile 33 year old Susan Beal who supports herself by sewing, quilting, embroidering and generally crafting various items (Slovic, 2007). A December, 2007 New York Times article profiled 24 year old Emily Martin who supports herself solely through crafting, most of which is sold through Etsy.com. It appears that the majority of this growing crafting community is women, aged mid 20s to mid 30s. The social and political reasons behind why this phenomenon has grown within this specific demographic will be discussed shortly in regards to third wave feminism.

\section{Craft and the Everyday}

In order to understand this movement, its political statement and its relation to feminism, it is important to understand women's work and craft in a historical context. The phrase arts and crafts has been commonly used in the past century. Sally Markowitz 
(1994) explained that Arts typically refers to items that we value for purely aesthetic purposes such as painting and sculpture. Crafts typically refers to ceramics, weaving, and woodwork and in particular to items that have a practical use. Art usually has a positive and arguably more elitist connotation than craft, which often has a more folk-oriented meaning that historically has been considered mundane. Some critics argue that historically what white European men have made is deemed art; what everyone else makes throughout the world is looked at as “only” craft. In this light, objects that have abstract contemplative value are considered art. Craft items then are most likely to be considered art only when the interpretation of aesthetic character is characterized less by aesthetic experience (its use or purpose) and more for aesthetic qualities (its appearance) (Markowitz, 1994). What historically was made by women or cultures and communities outside the elitist white, European art world was considered craft, and often not considered as valuable. Craft, because of its stipulation of having a specific use, is often associated with everyday life, as opposed to art, which may be considered above this.

John Fiske (1992) theorizes that one element of what determines the status of art (and subsequently that of craft as its subordinate) is its distance from everyday life. He argues that the separation of the aesthetic and social elements of art can only be afforded by elites who are not constrained by material necessity and who "construct an aesthetic which not only refuses to assign any value at all to material conditions, but validates only those art forms which transcend them” (154). The economically oppressed are unable to afford to make this separation from everyday life and of the aesthetic from the social. Because their art does not transcend every day use, it was viewed as craft. 
Fiske asserts that all oppression is economic, and that the everyday culture of the oppressed takes signs created by their oppressors and uses them for their own purposes. He looks at this oppression and at signs through the lens of studies of the culture of middle and lower class individuals and families performed by Williams (1998) and Leal (1990), and focuses on the texture of these lifestyles as a sign. Texture in this context is the richness, depth and intensity of experiences, practices and objects. The culture and lifestyle of these case studies of the oppressed is densely textured - from the exchanges on the street between neighbors, to the sounds and colors within their cramped and dense apartment living quarters. He comments on William's study of a middle class couple and description of their apartment which is cluttered with items - picture frames, a fake gold vase, a broken radio - all surrounding a blaring television. All of this creates texture.

This is the culture of everyday life. This culture uses the resources at their disposal to create texture as a sign. These signs (borrowed, as mentioned above, from the oppressors) are used to "fill their constrained lives with a variety of multiplicity of experiences that the more affluent can achieve by their greater mobility through physical and social space” (Fiske, 1992, p. 157). The creation of this texture and signs is art of the oppressed that is, making do with what they have.

Historically, it has been argued that the oppressed could and did use resources from nature to make do, however Fiske argues this is inaccurate, as the elite even then owned the land that contained the natural resources. The poor had to poach the resources they needed off of this owned property. This poaching became a part of the cultural and material activity of the oppressed. The creativity involved in poaching and making do with constrained circumstances arguably is a main element of craft. There are traces of 
the poachers, or of rural folk culture of previous generations, within the urban popular culture of contemporary capitalism. "Popular creativity,” Fiske says, “is concretely contextual. It exists not as an abstract ability as the bourgeois habitus conceives of artistic creativity: it is a creativity of practice, a bricolage” (1992, 158). This creative bricolage of the everyday is what produces craft such as quilts, diaries, and furniture. These products are created to "oppose and disrupt the organized, disciplined individualities produced by the mechanisms of surveillance, examination, and information which are the technologies of the mechanism of power. Popular differences exceed the differences required by elaborated white patriarchal capitalism” (161). The texture of everyday life is where these differences are practiced and where creative cultural artifacts - or craft - is produced.

The Early Arts and Crafts Movements

While there is still debate about what defines art from craft, there is a specific point in time when the vision of the craftsman morphed from that of poacher to become significantly elevated in not just the art world but in the mainstream and the everyday. The advent of industrialization in the 18 and $19^{\text {th }}$ centuries in Europe and America was expected to reduce the workload of the labor class through the use of machines, but eventually resulted in a degradation of all manual labor force. Long hours in loud, dirty, hot factories with low wages eventually gave birth to a rebellion that sought to reverse the takeover of artisans by machines. Labeled an Arts and Crafts movement, it was well underway by the early 1880s in Western Europe and its goal was to improve the quality of architecture and craftsmanship that society produced while improving working 
conditions for the middle and labor classes (Callen, 1979). The founders' ideal of this movement was to make creative freedom a right for all. It harked back to the years before industrialization and the division of labor by gender and class to when a single individual saw the creation process from beginning to end instead of one small portion of it, like when working in a factory or on a production line (Callen, 1979). An example would be an individual who raises and shears sheep, cleans, cards and spins the wool and knits a sweater using that wool, as opposed to an individual whose job is to work in a factory and use a machine to sew one garment over and over again. The forerunners of the movement believed that developing a workforce that allows individual creativity over the whole process would elevate pride in work and increase overall quality of what is produced. This movement lived among the working classes. The creation of handmade products or craft was the production of difference, subverting the oppressive power force that put them in difficult industrial working conditions. Crafting was a way to make do with what they had to create what they needed and eke out an income. It was also making do with what they had to make a political statement against industrialization. While this arts and crafts movement was politically, socially and artistically radical at the time, it actually perpetuated the dominant patriarchal ideology of the Victorian era (Callen, 1985). Instead of addressing the sexual division of labor like it intended to, the movement reinforced traditional male-female roles in relation to the production of craft, skills, and income. As industrialization grew, the home no longer was the center of productive labor as it was previously. It became a sanctuary and place of consumption, and it was the female responsibility to nurture it. Women were kept out of the workforce and kept inside the home and therefore were no longer producers of income for the family. In the 
industrialized era, this created issues for widows and other women without a man in the house to produce income (Callen, 1985). Because this Arts and Crafts movement would create the middle and lower class home as a place of production where women would be creating income through spinning, sewing, embroidering, woodcraft, and metalwork, it was expected to be a liberating force. However, it perpetuated a gendered division of labor.

Knitting, lace making and spinning were considered busy work that was not viewed as using intellectual capabilities. Bookbinding, jewelry and other metalwork that required finely detailed skills were also adopted as feminine busy work. Architectural work, stonemasonry, furniture making, ironwork and other work that required much training and/or a large amount of space was performed outside the home so remained the men's realm. Achieving the desired status of a master craftsman in the Arts and Crafts era required education and years of experience outside the home (Callen, 1979). This excluded women who were bound to their homes performing busywork. Thus while the Arts and Crafts movement sought to create work for women and elevate the status of the craftsman, it served only to validate the handiwork of white men and further subjugated women’s crafty “busy work.” This busywork and craft however, regardless of who was making it or what gender inequalities it perpetuated, was regarded as subversive to mass production and industrialization because it was handmade (Minahan and Wolfram Cox, 2007, p. 13). There are many parallels between the radical political and social elements of this Arts and Crafts movement, women’s role in it, and today’s crafting community. 
A handful of the most visible companies that supply the most recent handcraft movement with materials and online services are vocal about the political statement being made by the community they are involved in. For the 2008 holiday season, many of these companies, such as Etsy.com, craftster.org, Craft magazine and Sublime Stitching ask their customers to pledge to buy handmade. This involves entering your name and personal information into a website, www.buyhandmade.org. Doing so states that you “pledge to buy handmade this season and ask that others do the same for me.” Among other reasons, the website declares that a primary reason to buy handmade products is because:

The ascendancy of chain store culture and global manufacturing has left us dressing, furnishing, and decorating alike. We are encouraged to be consumers, not producers, of our own culture. Our ties to the local and human sources of our goods have been lost. Buying handmade helps us reconnect (www.buyhandmade.org).

The website collected over ten thousand signatures within two months over the 2008 holiday season, indicating the popularity of this sentiment. This call to reconnect to being a producer of culture and to eschew mass produced goods loudly echoes the similar call of the Arts and Crafts movement to reclaim production and creativity from industrialization. The players in the recent craft movement are encouraging the use of craft as a sign that individuals are able to make do with what they have in order to avoid the ill effects of mass produced consumer culture. According to the buyhandmade.org website, these ills include environmental degradation and the social-economic underclass caused by unfair trade with third world countries. The statement this organization and its 
pledges are making is that returning to being producers of cultural goods within the home by making do with items that are not a part of global manufacturing is subjugating the oppressor causing the aforementioned ills.

It is in this larger context that the community I am studying exists and creates the concept that Bourdieu (1983) calls “field.” In The Field of Cultural Production, he posits that artifacts (a book or piece of art) are products of not just the artist, but of the "field of forces" or "field of struggles" that is created by artistic position-takings. This is a jockeying of artists to create and leverage their cultural capital, which Bourdieu defines as a form of knowledge that equips the artist with a competence to decipher cultural relations and cultural artifacts. This is like economic capital in that it is unequally distributed among social classes, and the artistic field, like the economic, educational, political or any other field, is hierarchically organized based on the amount of cultural capital one yields. A work of art then, he suggests, only has meaning, interest and value for someone who possess the cultural competence to understand it.

According to Jameson (1984), this form of cultural capital has led to aesthetic (or artistic/cultural) production becoming integrated into commodity production generally. "The frantic economic urgency of producing fresh waves of ever more novel-seeming goods (from clothing to airplanes) at ever greater rates of turnover," says Jameson, "now assigns an increasingly essential structural function and position to aesthetic innovation and experimentation (p. 5).” The craft community, comprised of aesthetic artifact producers, is a part of this frantic economic cultural production, while at the same time making a statement against cultural commodification. As the aesthetic of the community itself becomes commodified, it continues to produce a new, novel aesthetic and artifacts 
to build cultural capital. This in turn fuels the ever-changing field of struggle and continues a discourse of existing outside the mainstream. This process is a constant exchange of cultural capital within the field of struggle. Each artifact produced is relevant in this field only because the community has the cultural competence to understand why it is a statement within and against a larger system.

Feminism and the Craft Community

There are other political statements being made by this community besides that of reclaiming the creative production process from the manufacturers of mass produced culture. This movement is also reclaiming traditional feminine craft by today's third wave feminists. In order to understand how and why the current handcraft movement is reclaiming women's work, it is important to review past feminist movements and how these evolved into the theoretical underpinnings of third wave feminism.

The first wave of feminism is documented to have started at the Seneca Falls Convention in 1848 and concluded with women's suffrage in 1920. The second wave arose in conjunction with the civil rights movement of the 1960s and 1970s as women came to recognize their own oppression. The second wave feminists fought for, among other equalities, inclusion and equality in the workplace, accessible reproductive healthcare, title IX, and acceptance to higher education. This wave has not yet had a defined conclusion as many of these feminists continue to fight for these equalities. The third wave of feminists grew up as daughters of the second wave in a world with these equalities (somewhat) in place, and are defined as having come of age in the 1980s and 1990s (Gilley, 2005). 
Because the notion of the third wave is recent and ongoing, a consensus among scholars has not been developed on what exactly it entails (Bobel, 2006). There are, however, several recognized tenets of third wave feminism that are criticisms of previous waves and of itself. One criticism is that second wave feminists painted a picture of feminism as bra burning, anti male, angry women, causing other feminists to not want to be associated with this image. A second is that all waves of feminism have historically addressed only the interests of its white majority while ignoring those of women of color (Gilley, 2005). Due to this, the third wave has looked at itself as not only oppressed, but also in a dual role as oppressor (Garrison, 2000). A third is its criticism of the second wave for striving to gain equality while pressuring women to attempt too much outside and inside the home. This exhausted women who were balancing careers in addition to their roles as wives and mothers (Gilley, 2005).

Because second wave feminists rejected women's work in a general sense in order to claim equality and also to balance work and life with male counterparts, women put down their needlework and abandoned crafting pursuits. Spinning, knitting, weaving and the like were viewed as belonging to their mother's generation and that this type of work was no longer necessary due to readily available manufactured items. This is not to say that crafting, quilting and the like have not remained popular among other generations, as forms of craft associated with more traditional female roles has (Walker, 2007). But the younger, third wave feminists are looking at women's work and craft from a different angle. They are the daughters of the second wave feminists who balanced career and home and are the granddaughters of those who still crafted - whether out of necessity or as a hobby. They value the idea of choice as central to feminism - women can chose their 
role instead of balancing all of them. Their reaction to the rejection of women's work by second wave feminists is to exercise this choice by reclaiming girly things such as knitting, crafting, and sewing (Gilley, 2005).

This notion of reclamation by third wave feminists arguably began with the creation of zines, cassettes and other items such as homemade menstrual products by members of the Riot Grrrl movement. This subculture of young women was born out of the punk subculture, which was launched in the 1970s in New York and London and created a subcultural production of style with an economic bent (Piano, 2002). The punk intent of buying and selling secondhand clothes and of a do-it-yourself (DIY) ethic was to exist in a new economy as producers of their own culture. The DIY concept, in full swing still, is to take cultural production into your own hands. Through trading and selling within the subculture market, an alternative economy is created that subjugates the mainstream. Women however did not play key roles in the scene and were largely left out of the punk movement. Riot Grrrl was born out of this exclusion to give women a voice in the movement and as an attempt to use “women’s subcultural production as a tool for political intervention” (Piano, 2002). It is built as a reaction against the assumption that young U.S. (predominantly white) young women are too preoccupied with material goods and themselves to be concerned with an understanding of and to have a reaction to politics (Garrison, 2000).

The Riot Grrrl movement has created subcultural spaces for "gender-specific cultural production and economies” (Piano, 2002). Zines are historically one of the most visible productions that are created and sold in their alternate economy. They are DIY magazines, often filled with personal and political statements that are either hand written 
or typed, photocopied, stapled or taped and are distributed, sold, and traded on websites or in person. Their purpose is to raise consciousness about political issues and to provide “access to and transformations of traditionally masculinist cultural institutions” (Garrison, 2000, p. 143).

The women zine producers are entrepreneurs connected to each other and their subculture through their production and distribution of these cultural products. They are creating and consuming outside the dominant economy, and in this way are using consumerism as a form of activism. These zine editors and publishers are making do with what they have, using paper, pens, staples and tape to produce cultural artifacts. Other DIY make do products quickly joined the zine market - cassette tapes, hand made and screened t-shirts, handmade menstrual products, soaps, patches and stickers (Piano, 2000). Many of these items are sold online (including on Etsy.com) or knowledge of them is spread online through forums and chat groups. However, many zine editors did and do not want to make the virtual leap due to limited access for those who cannot afford nor have access to computers. While some zines are online, the market for exchange of hardcopies still remains very much offline (Garrison, 2000).

Ednie Kaeh Garrison explains that for subcultures, it is becoming more necessary to combine style and politics as a tactic in a cultural-historical period marked by "the logic of late capitalism” in which the commodification of resistance is a form of hegemony (143). The Riot Grrrl zines are political texts and their distribution networks are central to the third wave feminist movement culture. This network provides an opportunity for the subculture to control their own conversations and to connect different nodes of the movement (2000). The alternate economy this creates is intended to exist 
outside the "logic of late capitalism" Garrison discusses. The act of "making do" to create these cultural products is the art and craft of the oppressed creating texture, or signs.

This DIY ethic of the Riot Grrrl movement, and their reclamation of other things girly in areas such as in fashion (baby doll dresses and knee high socks for example) has evolved into women's work and craft. The making of soap, t shirts and menstrual products by hand has grown to include sewing, knitting and crocheting of clothes, scarves, purses, and other crafted items. This brings us to the near present, when third wave feminist Debbie Stoller, publisher of Bust magazine (which began as a zine in the era of the Riot Grrrl subculture) wrote Stitch $n$ Bitch and contributed to the popularity of knitting. Today’s crafters are very aware of the feminist and political underpinnings to this movement. Susan Beal, the aforementioned crafter profiled in a Portland, Oregon weekly newspaper says “The fact that I can earn my living with my creativity feels very feminist to me. I don't know if I would say it’s the new bra burning, but I definitely think it's a radical act to make something that's homemade when it's so easy to buy something that was made in Bangladesh” (Slovic, 2007). She acknowledges that it is a reclamation “of what generations before her devalued or took for granted.”

The handmade craft items fully utilize the DIY ethic of this subculture, and distribution of them exists in the same alternative economy as zines, cassettes and other Riot Grrrl cultural productions. The products are sold at craft fairs, which are often gatherings in a park or in a family owned restaurant or coffee shop that has extra space. Often small art galleries remain open at night to serve wine and allow crafters to exhibit their handmade wares. They are also traded for other crafts or services such as massage, graphic design, or painting. Partaking in this alternative exchange community is an 
opportunity to exist in an economy outside the dominant hegemonic culture. It is a space for women to be more than just consumers, as is the current capitalistic society expectation of women. They become creators of culture and community on their own terms. The DIY concept and craft in particular has become central to how young women are producing culture to create "alternative feminine identities and media that resist mainstream representations” (Piano, 2000). Pledging to buy handmade is one of the ways today to identify oneself as a member of this subculture.

Technology, Feminists and Craft

While much of the interaction between Riot Grrrls occurs off line, one cannot ignore the strong online component of this subculture. Garrison (2000) argues that oppositional technologies are the "political praxis of resistance being woven into lowtech, amateur, hybrid, alternative subcultural feminist networks that register below the mainstream” (151). This includes, as mentioned earlier, photocopiers for zines, but also simple free online software such as forums and blogs. The third wave is a network built on these specific technologies and Riot Grrrls have created nodes that are points of networking and clustering within the technological communities (Piano, 2000).

The considerations of women and technology are an important feminist concern. In this setting, technology refers to continually-evolving high tech tools such as computers and intricately programmed websites. The history of women being excluded from the men's club of math and science extends to today's computers and technologies which remains a male dominated field (Flew, 2002). Historically, the introduction of technology such as the sewing machine and the automated office intended to make 
women's lives easier as these machines directly affected their jobs. It resulted however in fewer jobs and more difficult working conditions (Smith and Balka, 1988). Judy Smith and Ellen Balka (1988) coined the suggestion that a Sex Role Impact Study (SRIS), based on the Environmental Impact Study (EIS), be done on how technology would affect women's lives before it is introduced, similar to how an EIS is performed before implementing a new land use development. They argue that some questions should be: "Would it (the technology) broaden or restrict women's traditional options? Would it increase or limit women's chances for economic self-sufficiency? Would it increase or decrease women's mobility?” (84). Smith and Balka concluded that while there is a mix of costs and benefits involved in the use of technology, email, forums and other technology can be a useful tool in quickly congregating women for a rally or fundraiser. It also provides quick access to information such as feminist libraries and other information resources.

These questions of the issues between women and technology apply to the craft community's use of websites, blogs and the like. While there is the issue of technology excluding those who can't afford to partake, there are also benefits to its use. The first is its primary function of creating a method of communication between different geographic nodes of people. Garrison (2000) suggests that dissemination of a subculture's political and cultural productions is facilitated by democratized technologies that proliferate and construct "different, counterpublic sites of resistance" (157). It functions as a method of communicating and creating outside of the mainstream media. Technology plays an integral role in allowing Riot Grrrls and other young women to raise consciousness of 
major issues through the creation of web pages, blogs, and online stores so they can operate locally and nationally within their own alternative economy.

Etsy.com and Feminism

As mentioned earlier, Etsy.com is a recent technology employed by the crafting community. Etsy allows users to create their own online shops to sell handmade goods (the website charges the seller a flat fee for every item sold). It also provides forums where users can exchange information on DIY techniques and publishes various Etsy shop-owners business profiles with narratives about why and what they craft. Etsy is a valuable tool to crafters as it allows them to sell their goods to an international market as opposed to the only local audience that would visit a craft fair or boutique shop. It taps into the geographically disparate nodes of online third wave feminists that Garrison (2000) points out as having been created by technology. Individuals’ involvement in Etsy and other interactive technologies strengthens the community and alternative economy through commerce and easier communication over distances. "Plugged in” individuals can quickly and easily find a plethora of information from multiple sources. The Craft Yarn Council of America found that 31 percent of knitters they studied found their knitting patterns online. Many crafters post their knitting and sewing patterns and techniques online for free or for purchase, all of which are available 24-7 to those who look for them.

Historically, a site like Etsy.com might be viewed an example of technology leaving women behind. In the past, women would be expected to shy away from the male dominated world of new technology, but, as can be seen by the Riot Grrrls’ use of 
technology, this is no longer always the case. Many women entrepreneurs have hung their shingle on Etsy.com. And in alignment with the Riot Grrrl legacy, these women use free and low cost technologies such as blogs, forums, photo sharing sites (such as flickr.com) and other online nodes to market themselves and drive traffic to their Etsy shop.

As Garrison described, these tools serve the purpose of creating a space to communicate with each other and as a form of political self expression. Many blogs that Etsy shop owners maintain include information that is completely unrelated to their shop. The Black Apple, as mentioned earlier, is an Etsy shop owned by Emily Martin that sells her art, homemade dolls, clothes and other craft goods. She also maintains a blog at www.theblackapple.typepad.com. She posts about her painting and when her next "shop update” will be on Etsy that will feature new products, but she also talks about completely unrelated items, such as recipes, movies and current events. Other blogs discuss similarly unrelated topics: the blogger that maintains www.acunningplan.typepad.com discusses everything from marketing campaigns she observes, weight loss and politics to her children's birthday presents. Creating and reading these blogs provides a space for political discourse among these women. Each blog is a personal narrative and cultural product which exhibits the third wave feminist characteristic of being focused on the individual and the narrative. It creates a space that is personal and political, while also relating to their production of income. Additionally, the combination of production and personal in the blogs and on Etsy harkens back to the Arts and Crafts movement. During this era, the ideal craftsperson is one who claims the 
entire creative process of production to themselves and relates the production of goods and income directly to the personal.

Using Etsy, blogs and other technologies that are readily available and inexpensive is another method of making do with what is available and is central to DIY and crafting. This making do is the cultural and material activity of the oppressed (Fiske, 1992). The poaching of everyday resources and ideas creates the texture of everyday life that Fiske describes, and is demonstrated through the resourcefulness of the recent craft community. Technology facilitates the sharing of ideas, making the poaching easier. One crafting website (www.counterfeitcrochet.org) features patterns that show crocheters how to craft their own knock off designer purses, creating subversive items and a political statement against the expensive purses that are advertised to women in the mainstream media. The website encourages users to create their own patterns and to share them on the website, creating a node of community for women who share the goal of making a political statement against capitalist culture. Making do and crafting knock offs is the antithesis of buying into this capitalist culture. The motto of the website is "viva la revolution!” I interpret the revolution as that of the creation of the women-controlled alternative economy that subjugates mainstream manufacturers and media that Piano discusses.

The creation of Etsy for crafters however poses an issue for the subcultural status of the craft community. Etsy founder Rob Kalin is given credit for "spotting the business opportunity” for creating the company into what it is today. His background is in computer programming and was an admitted techie type that didn’t know much about the handcrafting movement before he was approached by the founder of Etsy’s precursor 
getcrafty.com (Walker, 2007). Kalin and some of Etsy’s best sellers have appeared in the New York Times and on Martha Stewart, indicating that mainstream media is just picking up on this subculture and likely stands to benefit from the commodification of it. If Etsy was created for and is profiting from crafters, then their use of it is no longer "making do” in Fiske’s terms. The community is no longer using the alternative methods of economy that they've created and they no longer exist outside the mainstream. This may mean they have or will become a market themselves that the capitalist society that they are rebelling against is attempting to tap into. The community may be reaching a point where its resistance is becoming commodified by that which Garrison (2000) explains they are trying to resist.

Regardless of if Etsy is seen as a friend or foe of the movement, it would be beneficial to take Smith and Balka's aforementioned idea and look at Etsy.com and similar technologies and perform a variation of the SRIS (Sex Role Impact Statement). Does Etsy broaden or restrict women's traditional options? Does it increase or limit women’s chances for economic self-sufficiency? Does it reduce or increase women's privatization in the home (Smith and Balka, 1988, p. 84). What are the correct answers to these questions? As technology continues to develop, determining its effects on gender, communities and cultures will remain a moving target. While the craft movement has many similar political intents to the turn of the century Arts and Crafts movement, there likely are similar pitfalls that would perpetuate dominant methods of control. A continuing analysis of the technological tools that create space for a community where women are able to make political statements will help avoid history repeating itself. 


\section{Chapter II: Research Methodology}

As stated earlier, the broad purpose of this analysis is to understand the implications of online communities such as Etsy.com on the communities they serve. More specifically, I am curious what role technology, and Etsy.com in particular, plays in the lives of women who are a part of this subculture. In order to understand this, I chose ethnography as the research methodology in order to provide a thick rich description of the culture sharing group that uses Etsy.com, its political intent, and the role Etsy.com plays in their community.

\section{Ethnography}

Bickman and Rog (1998) describe ethnographic studies as allowing multiple interpretations of reality and alternative interpretations of data. Ethnographers understand and describe social and cultural scenes from an insider's perspective (p. 474). The underlying framework for this study is based in the critical paradigm. Silverman and Marvasti (2008) state the goal of this type of research is social theorizing in order to comprehend and possibly transform underlying orders of social life through case studies or ethnographic accounts (p. 81). This study is also based in feminist literature, and in studies that use this approach, the researcher is often placed in the study "so as to avoid objectification,” which ethnography would allow. Silverman and Marvasti also state that feminist researchers "see gender as a basic organizing principle that shapes the conditions of their lives. It is a lens that brings into focus particular questions” (p.83). I see gender and the experience of women as a basis for the meaning being created by this web-usebased community. Ethnography as a methodology allows themes to emerge from the data 
and the researcher to focus on and address what appear to be the most important questions that arise as a result. I have chosen to apply a critical and feminist analysis to the central themes that emerged during the research.

Willis, in his book The Ethnographic Imagination, explains that cultural methods of meaning making "are intrinsically self-motivated as aspects of identity-making and self-construction; in making our cultural worlds, we make ourselves.” This identity creation, he says, is done through "creative cultural practices which produce something that was not there before, at least not fully or in the same way" (p. xiv). Willis is referring here to the creative and imaginative aspect he says is part of performing an ethnographic study. The commentary on identity-creation through creative cultural practices applies directly to the community I am studying. Therefore, I find ethnography, as a cultural production, an appropriate method of studying a culture producing group.

\section{The Community}

For this study, the community of Etsy.com users and crafters is defined as individuals who use the website to sell items that they have made by hand. This includes hand crafted items that are sewn, knitted, painted, cut and pasted, welded, printed, and so on. Participants could include anyone from a painter, a maker of clothing, jewelry or stationary to a potter, welder or sculptor. Several participants in this study generate the majority of their income from selling crafts, and at least part of that income is from sales through Etsy.com. These crafters, as a part of an in-person and online community, also sell or trade crafts through stores and fairs and generally do not use Etsy.com as their exclusive method of income from crafting. Several participant crafters also maintain 
blogs and generate other online content and publish in print. These artifacts were used for analysis in the study.

I gained access to this community in several ways. First, I have a close friend who sells on Etsy.com, participated in an interview, and referred me to others. Additionally, as a volunteer at Portland's Independent Publishing Resource Center (iprc.org) in spring and summer of 2008, I became acquainted with several self publishers who are members of the community and gatekeepers for access to other informants. This volunteer experience at the IPRC began out of a community based learning (CBL) course at Portland State University in the Spring term of 2008. The IPRC provides the space, tools and other resources to encourage self publishing. While volunteering there, I worked with members of the non-profit who are self-publishers that are at the center of Portland's local, inperson hand crafting punk subculture. As a part of the CBL course, I took field notes while volunteering and conducted several interviews with members, volunteers and management at the IPRC. I wrote a paper that contextualized the experience in theory. The volunteer experience and resulting paper deepened my immersion in this community, beginning my ethnography in earnest and planting the seeds for this study.

There are many sub communities within Etsy.com based on physical proximity, type of craft, level of use of Etsy, reason for crafting and other factors. Johnson, in Selecting Ethnographic Informants (1990), explains how in large communities (such as the one using Etsy.com) true random sampling is not possible or desirable, and that in large populations, a straight random sample of the population may not yield enough cases that are of theoretical interest. Therefore, he says, the criteria for selecting informants for ethnography may be factors that the ethnographer deems theoretically important. Gaining 
access into several of these sub communities through these various gateways allowed me to collect a variety of data from a range of sources, and find those informants that were of theoretical interest and that are members of the specific sub community I am studying. Because the purpose of ethnography is to create a thick, rich description of one specific culture sharing group, it is not necessary to collect and use data from each of the various sources or cultures within the larger community. I have observed a community of feminist crafters on Etsy.com and selected informants that fit this theoretical framework.

Kimball and Partridge, in The Craft of Community Study (1979), explain how when studying community, untrained observers may view the diversity within a community as discrete and independent of each other. However through the study and creation of a thick rich description of a community, one can see the interdependence between parts of a seemingly non-uniform community. This is similar to the very large community that uses Etsy. The members are tied together by their handcrafting and use of the website. It is important to acknowledge that I did not consider all members of Etsy.com as part of the same culture sharing group. The nature of Etsy.com popularizing craft to the mainstream means that the initial meaning in the act of handcrafting has been to some extent stripped away, which happens (as described in the earlier literature review). It is likely that many individuals that sell their wares on Etsy.com are unaware of the feminist foundation to the community. I assume there are many Etsy.com users that are unaware of getcrafty.com, Debbie Stoller, Riot Grrrls or other early players in this phenomenon that are outlined in the literature review. There are also many who do not sign the "Handmade Pledge" or share those values. While a part of the larger community, they are not a part of the sub culture that this study looks to analyze. I selected informants 
who I either know well enough to understand their motivations for what they do, or know through acquaintances or reading other material they have published that they share a similar political basis behind their crafting. As Johnson describes, I selected participants that are of theoretical interest.

While I do not fit the criteria of a participant in this study since I do not earn an income through Etsy, I am a member of the larger community. I have a personal curiosity and interest in the phenomenon of this particular community using the Internet as I've watched the popularity of both crafting and social networking sites grow in recent years. I purchase many items on Etsy, read and comment on crafter's blogs, participate in local knitting groups and visit local craft shows. My volunteer experience through the CBL course at the IPRC was also invaluable. Interacting with and analyzing my experience as a member of the culture through a critical lens influenced the direction of this study early on. Due to the self-reflexive and cultural immersion nature of ethnography, this experience is an asset to the study.

Additionally, this experience puts me in the role of a participant observer of the community. Spradley (1980) explains that ethnographers do not merely make observations, they also participate (p. 51). Ordinary participants in an activity or community come to a situation with the sole purpose of engaging in the activities; participant observers engage but with the purpose of recording findings as well. The typical person is continually filtering their observations and experiences to avoid “overload,” which Spradley describes as a “system’s inability to process inputs from the environment because there are too many inputs for the system to cope with (p. 55).” The participant observer on the other hand seeks to become explicitly aware of things usually 
blocked out to avoid overload. This requires the ethnographer to increase his or her awareness in order to raise the level of attention to tune in to things that are usually tuned out. The participant observer also approaches the setting to be studied with a "wide-angle lens,” which allows the researcher to take in a much broader spectrum of information, such as the political context a community is operating within (p. 55).

Data Collection and Analysis

The primary method of data collection was through interviewing these members of the community. Two of the interviews were in person, as the interviewees were in the Portland, Oregon area and were comfortable with meeting. The remaining three interviews were done by phone, as it was more convenient for the study participant. While I used an outline of questions to ask all interviewees, the interviews were actually quite informal and not firmly structured. Bickman and Rog explain that informal interviews in ethnographic studies are used for “discovering what people think and how one person’s perceptions compare with another's.” These help the researcher “identify shared values in the community - values that inform behavior” (p. 481). Silverman and Marvasti state that research interviews that use a feminist approach are often conducted in an "interactive, dialogic manner that entails self-disclosure on the part of the researcher and fosters a sense of collaboration” (p. 83). Each interview was very unique and dynamic based on interviewee responses and very conversational in manner, as researcher inclusion and self disclosure in the research environment are an element of ethnography and studies that are based in a critical, feminist framework. Questions were open ended and depended on previous answers received, allowing the exact interview 
topics to be fluid. Silverman and Marvasti also explain that an element of feminist studies is that researchers negotiate the meaning and co-create meaning with participants in studies (p. 84), which a flexible, informal interview structure will allow. I interviewed 5 individuals total from the community during spring of 2009, and the discussions covered relatively similar content with recurring themes that pertain to feminist and critical theory. In order to analyze content for recurring themes that appear in their responses, I recorded and transcribed these interviews shortly after conducting them.

Maxwell states that memos, as an analytic method, serve to help the researcher reflect on methods, theory and purpose in order to facilitate analytic insight (p. 96). I took notes during the interview, wrote memos immediately following, and did so again immediately after reviewing the transcribed content. I then used these memos and additional notes as I read the transcripts to place interviewee responses into categories. Information was placed into two types of categories: one that contains information that pertains to creating a thick rich description of the community. The second type of information falls into thematic categories; these categories were emergent and determined after an analysis of the memos.

While reviewing the data and taking notes, I began to see patterns in the interviewee’s responses. For example, I noticed a couple interviewees used the term "saturated” to describe the amount of content on Etsy.com. Most of the interviewees referenced this sentiment - that it was becoming more and more difficult to differentiate your shop on Etsy. This leads to the artist/business owner spending more time on the computer marketing the business rather than making art or crafts. The more I reviewed the data, the more patterns like this that I saw emerge. I designated a color for each 
pattern, reviewed the data with these patterns in mind and highlighted text the appropriate color based the pattern it contributed to. It was in this way that I saw patterns and then themes emerge from the data I reviewed. The researcher brings their own lens to what themes they see emerge in the data, and facilitates the analysis of these based on what they see as a relevant. In this case, it was a critical feminist approach that was most relevant to this researcher.

In addition, I conducted a textual analysis of relevant blogs, marketing materials, artwork and other cultural productions or publications created by women who are a part of the community. Van Manen (1990) states that logs, journals and other writings (or artwork and cultural productions in this case) "contain reflective accounts of human experiences that are of phenomenological value” (p. 73). I began reading craft blogs (web logs, which are essentially online journals in many cases) around mid 2006, but did not do so with a lens for this type of research until early 2008. I began saving links to specific posts on blogs that I found relevant to my research in a Microsoft Word document. As my thematic categories began to firm up for this research, I was able to sift through these posts to determine if there was relevant content and how it related. Note that there are numerous additional blogs besides the following that influenced my participation and understanding of the community. Many of these bloggers have also written books and conducted events (book signings, sewing classes, and so on) that I have attended in the Portland, OR area. Each of these blogs is focused primarily on knitting and/or fiber arts, although posts vary to include recipes, vacation photos, home decorating/remodeling photos, fundraising, gardening and so on. http://acunningplan.typepad.com/ 
http://allbuttonedup.typepad.com/all_buttoned_up/

http://angrychicken.typepad.com/

http://a-friend-to-knit-with.blogspot.com/

http://blairpeter.typepad.com

http://crimsonpurl.blogspot.com

http://frenchpressknits.blogspot.com/

http://mysensitivegirlhole.blogspot.com/

http://jchandmade.typepad.com/jc_handmade/

http://spiderwomanknits.typepad.com/

http://www.cosmicpluto.com/blog/

http://www.flintknits.com

http://www.theblackapple.typepad.com/

http://www.kittygenius.com/

http://www.yarnharlot.ca/blog/

Thematization

Van Manen states that themes are "knots in the webs of our experiences, around which certain lived experiences are spun and thus lived through as meaningful wholes” (p. 90). The purpose of thematic analysis is to recover "themes that are embodied and dramatized in the evolving meanings and imagery of the work” (p. 78). This process is intended to reveal the meanings embedded in lived experience and create a structure for this experience. Analyzing the above artifacts and other data for themes in relation to theories and literature is a recursive process that results in a triangulation of theories with 
the themes, with the purpose of analyzing the data on a deeper level to understand the meaning of a phenomenon. Bickman and Rog (1998) claim triangulation is basic in ethnographic research and is at the heart of ethnography's validity. Testing one source of information against another verifies the quality of the information and puts the situation under study. The themes that emerged from interviews and artifacts are relevant to feminist and critical theories. As can be seen in the literature review, the emergent themes revolve around why women craft and partake in this community and why and how they use Etsy.com. 


\section{Chapter III: Findings}

Presentation and Analysis of Data

The analysis of data in this chapter is divided into two categories:

- Data type 1 is characteristic data that provides a thick rich description of the community. This includesdescriptions of the interviewees and bloggers, and descriptive passages that provide a general depiction of the community.

- Data type 2 includes thematic data and discussion that relates to the larger theoretical framework outlined in the literature review.

Both sections include data from interviews and online sources of data, such as blogs. The actual passages of interviewees' words are indented and single spaced, and start with the interviewee’s initials (NG, AF, AG, RC). Passages from different interviewees are separated by three asterisks $(* * *)$. When there are passages from the same interviewee that are from different parts of their interview, there is a line between the passages and the next passage is again started with the interviewee's initials. Passages from blog posts are quoted, and the entire blog posts as it appeared on the blog, including comments from readers, are included in the appendix.

\section{Data Type 1: Thick rich description}

The first type of data that is presented and discussed includes interviewee responses from participants and other narratives published online that create a thick rich description of the Etsy.com crafting community. These narratives reveal social structures within the community, describe how the community functions and operates, and shows how the community addresses change and conflict. These statements in general paint a 
picture of several individual members while also describing the Etsy.com community in general. Overall, the data shows how Etsy.com and similar technologies (blogs and community websites such as ning.com and bigcartel.com) affect the daily lives of the women who are a part of the community.

As discussed in the methods section, data was collected several ways, including through interviews with community members, from blog posts and other content from community-related websites, and from content on Etsy.com shops, forums and blog posts on Etsy.com. As outlined in the parameters of who may be appropriate informants for the study, I interviewed individuals (4 women and 1 man) who earn income through their Etsy.com shop. The profiles below of each of the interviewees provide context for their statements which are the basis for this study.

Participant Profiles

Participant 1: "RC”

I interviewed RC by phone. She is a lifelong friend of mine who has owned an Etsy.com shop for several years and lives in Milwaukee, Wisconsin. She earns all of her income through her artwork, and a significant portion of it through Etsy.com sales. She is 29 years old as of spring 2009 (when the interview was conducted) and is a formally trained artist, having majored in art in her undergraduate studies. She sells many of her paintings and photography, and also sews purses, wallets and pouches that she sells in her Etsy.com shop and at craft fairs. She also paints murals when possible, and for health insurance she works part time painting signs for Trader Joe's, a national grocery chain. 
She was involved in the craft community before finding Etsy.com but has met other crafters and business women through the website.

Participant 2: “AF”

I interviewed AF by phone, as she is a friend of a friend who lives in Scottsdale, Arizona. She is in her early thirties, and uses Etsy.com to supplement her full time work as a graphic designer. She was introduced to Etsy.com by a friend and found inspiration on the website to create custom stationary and cards. She does not sell items anywhere other than Etsy.com, although she purchases items from craft fairs and other craft community-related events in her city. She hopes to someday own her own crafting business, either online or a bricks and mortar (or both) that sells stationary and sees her Etsy.com business as a launch pad to doing this.

Participant 3: “AG”

AG lives in Portland, Oregon and I interviewed her by phone. I found AG's artwork, Etsy.com shop and her blog through another artist in the community whose blog I read and whose Etsy.com shop I have purchased from. I have commented on AG's blog a couple times, as she refers to areas in Portland that I am familiar with. Her Etsy.com shop supports herself and her partner entirely with no outside income sources. She is 28 years old as of spring 2009 and grew up in St. Louis, Missouri where she was involved in the fashion business. Her boyfriend found Etsy.com, told her about it, and shortly thereafter she began selling several pieces of jewelry she made. She eventually began selling digital prints of her paintings and the business took off. She moved to Portland, 
Oregon about a year ago to be closer to people she met through the Etsy.com community who also had moved to Portland. Her boyfriend now works full time for her business. As of spring, 2009, she was the number one seller in the art category on Etsy.com and has received significant recognition, promotion and support from Etsy administration.

Participant 4: “NG”

I met NG at a coffee shop to interview in person. I knew of her through my volunteering at the IPRC as someone deeply involved in Portland's self publishing community. She maintains a blog, zine and Etsy.com shop, although I was aware of her mostly through her zines and involvement in a local arts nonprofit. She is in her early thirties. Her income is generated entirely from her artwork, although only a portion of it comes from sales on Etsy.com. She sells in craft fairs and other events and paints portraits, which she gets through referrals and her own website independent of Etsy.com.

\section{Participant 5: VG}

I interviewed VG in person in a coffee shop on the Portland State campus. VG is an undergraduate student in the same department I study in. In addition to being a full time student, he owns a business creating large scale artwork and custom decorative screen-prints for businesses. A portion of this business involves selling items in an Etsy shop. I met him through a member of the faculty that was aware of my research and put us in touch. Due to the noisy location of the interview, the interview recording was difficult to understand. I was able to transcribe notes and only parts of the interview. Due to this, I was not able to include his complete passages in this analysis. He was the only 
male participant I interviewed, and although I am unable to include the data he provided, I do know that several of the themes I saw emerge in the earlier interviews were present in his interview as well.

Online Sources from the Community

As mentioned previously, data was also collected from online sources and then triangulated with the interviews and other resource data. Online community sources included blogs maintained by community members, websites that serve the community, and Etsy.com itself. These sources provide data that is quite different from the interviews, as the data is obtained without having to acquaint oneself conversationally with the source. The back and forth involved in interviewing allows the researcher to collect data interactively. Online sources however are static in that there is no immediate back and forth between researcher and community member like there is during an interview or conversation. The data (a blog post or piece of artwork) is readily available via a webpage, but the researcher is of course not always able to reach out to the blogger or artist directly to discuss their experience in more depth. In the case of blog posts, a reader is able to comment and the blogger can respond via email or the blog to comments. Several blog posts with comments that are referenced within the analysis are included in the appendix to show the communication between blogger and readers in the community.

The following is a list of online sources referenced in this research. There are thousands of other bloggers that maintain Etsy shops, blogs and other online profiles (such as Ravelry accounts) that are relevant to this topic. Because websites and blogs 
come and go frequently, screenshots of community web pages that are quoted are included in the appendix to document content.

Profiles of specific bloggers and their posts referenced in this research are described below.

1. Blogger: Blair Peter

Blog: http://blairpeter.typepad.com/

Specific post referenced in analysis:

http://blairpeter.typepad.com/weblog/2008/10/portland-i-shou.html

Description: Blair Peter blogs primarily about crafting, including quilting, crocheting, home decorating and other creative topics. Her topics are almost exclusively domestic, including posts about her kids’ interests, recipes, and other home endeavors. She frequently references other bloggers that post similar content (as outlined in the post included in my analysis). She and her husband own several businesses and their work is frequently promoted by other bloggers.

2. Blogger: Pamela Wynne

Blog: http://www.flintknits.com/blog/

Specific post referenced in analysis: http://www.flintknits.com/blog/?p=171

Description: Pamela Wynne posted mostly about knitting initially. She adapted a popular old baby sweater pattern that was first published by Elizabeth

Zimmerman (a famous knitter that designed patterns and self published them in a newsletter decades ago). She named the pattern "February Lady Sweater," and it was knit and blogged about by a popular blogger, Stephanie Pearl McPhee 
(www.yarnharlot.com). This caused the pattern to "go viral," or catch on in the community, leading it to be one of the most popular knitting patterns in the online community. I myself have knit this pattern. This experience led her to become very visible in the community, and led to her post above about patterns and copyrights that I include in the analysis below. Pamela's blog posts continue to be primarily knitting focused, although with political commentary. A recent post included a long analysis of the works of Ayn Rand as it relates to a knitting pattern she found online (blog post found here: http://www.flintknits.com/blog/?p=198).

3. Blogger: crimsondiva1999 (her virtual identity) Blog: http://crimsonpurl.blogspot.com/ Specific post referenced in analysis: http://crimsonpurl.blogspot.com/2009/06/tippy-toe-knitting.html Description: Crimsondiva1999 posted regularly for several years about knitting, but no longer maintains the blog (although as of this writing the account is still live and accessible online). She posts frequently about meeting in person knitters she has met online, friend's knitting projects through her local knitting shop, and at times about other personal matters. She now maintains a separate blog on a different topic (running as a fitness hobby).

\section{Blogger: Heather Armstrong}

Blog: http://dooce.com/ 
Specific post referenced in analysis: http://dooce.com/2010/04/08/dc-part-two

Description: Heather Armstrong is a blogger with a very large readership. While I do not know the number of daily page views and readership of the blog, the income from her blog maintains her family of four. Her notoriously personal blog about her family, job, friends, mental illness, fashion and other interests led her to write several bestselling books on post-partum depression. She has spoken at the White House on women and the home workplace, has a television show on HGTV (a cable television station) and has raised funds for many non profits via her celebrity status.

Industry websites (these serve the community by selling goods or services)

- http://www.etsy.com

o An online marketplace for homemade goods. The basis for this study.

- http://www.buyolympia.com/q/

o Also an online marketplace for homemade goods. It was founded before Etsy.com, but remains a small, independently owned organization.

- http://www.craftyarncouncil.com

o The website for the Craft Yarn Council, an industry association.

- http://www.tnna.org

o The website for The National Needle Arts Association. The organization hosts a very large industry event each year where many individuals who meet online are able to meet in person.

- www.ravelry.com 
o A social networking site focused on fiber arts. Members create profiles, post photos, patterns, yarns and other details on craft projects.

- $\quad$ http://etsyaoc.ning.com

o A social networking site for Artists of Color who sell their products on Etsy.com

Descriptive Passages: Themes that characterize or describe the online community

The following passages (and corresponding discussion) from interviewees and bloggers outlined above provide a rich description of the community in several members' own words. After reviewing data, the passages were organized into three categories that emerged from the analysis:

1. The Etsy.com Community

2. Community Saturation

3. Dealing with Conflict

The passages and discussion woven throughout also provide context for the discussion on thematic categories included in Data type 2.

\section{The Etsy.com Community}

Each interviewee described how the community and its members are organized and refer to different types of users on Etsy.com. This highlights the subcommunities within the website based on the "type" of Etsy seller. These are determined by why they use it (as a hobby or for income), the aesthetic of what they make (modern or folk), do they promote themselves online or offline, and so on. These descriptions paint a picture 
of the hierarchy of individual users, the subcommunities they belong to, and how the Etsy community interacts with the "offline” craft community.

The following quote reveals how sellers are categorized based on how much they use Etsy versus selling “in person.”

NG: I mean it is kind of crazy if you're trying to get people you've never met before who don't know your work to buy your stuff. Because you have to just live on your computer which I'm not sorta, big on. ${ }^{1}$

The reference to the sub communities and their hierarchies help us see how the larger Etsy.com online community functions as a whole that is made of separate parts. This statement shows that NG doesn’t see herself as the type of community member that spends all her time on a computer in order to sell her work. She goes on to say:

NG: I think people that are Etsy people, they have to post everyday and have a blog that goes on their Etsy page and be in the Etsy community page. I just don’t feel like I have the energy to do that.”

She refers here to Etsy users who market and sell their work exclusively online, and indicates she does not want to be one of those people. As mentioned in her profile, NG sells a lot of her work offline and is involved in the local arts community as opposed to the online community, which explains her distaste for spending all day on a computer to sell her work to those outside the local, in person community.

She refers to another divide within the community that is based on not how, but why people use Etsy.com.

NG: I think it's because there are people that do it for a job and people that do it for a hobby not for main income. Or there's a lot of privileged people with a lot of extra time that they can do it just as a hobby and don't have to worry about making a wage off it. Because I work as an artist, I'm like, I have to get paid for this. 
She describes the difference between Etsy.com users based on their amount of use and how this affects their daily activities - some users spend most of their time on a computer to obtain business through Etsy.com while others use multiple tools that are offline. She also needs to make an income from what she makes and needs to charge a realistic price for her wares. The placement of herself as a certain type of Etsy.com user who doesn't do certain things (spend all day on a computer, craft as a hobby and charge low prices) shows us that there are many types of Etsy sellers with different motivations and goals. In the following quotes, interviewee RC differentiates between Etsy.com community members not only by how much time they spend on their computer, but also by the aesthetic of what they make and the materials they use.

RC: There are totally different populations of people on Etsy. Some people are just making really cheesy country crafts and stuff. The other kind of cool funky people who might have a part time job or full time job and do it for fun. It's pushing more into the people who quit their jobs and do it full time. Then there are the people who have thousands of sales, and they totally do it full time and are super busy. There are lots of different types of people. Lots of users are just buyers. I think there are a lot of people who fizzle out and their shop is empty. Like me - I only have 9 items for sale, but am busy with other projects... You see A LOT of that - scrapbook prepackaged materials. And it gets annoying too because it really clogs up the system. And like the other thing that clogs up the system is their whole vintage thing. And they are like adamantly all about that... So like keep it, but maybe make another site for it, like Etsy vintage and Etsy supplies... Cuz its cool to have it, it is like a whole online super store full of cool stuff, but then its just gotten so big, that its like, each one could stand on its own. ${ }^{2}$

The following statement from the same interviewee further describes hierarchies

within the community and discusses how these have evolved.

RC: I think that it is definitely getting inundated with more junky crafty stuff. You know like if you'll try and do a search you'll get a million more pages than before and you have to filter through a lot of it. It's just how it's gotten a lot more like using journalism and reading different articles and just trying to get more involved with the craft community. 
Her comments that refer to "throwing junk up there” and "clogging the system” reveal a hierarchy of Etsy.com users based on what they sell - both the function of it and its aesthetic. This is referencing a hierarchy based on Bourdieu's concept of cultural capital within the larger Etsy community. In this instance, the interviewee attributes the existence of the different parts of the community (based on what they sell - supplies vs. art, vs. craft) to the company model ("it must be a huge market for them. They're not going to really let that go”). The community discusses this model (of allowing the sale of supplies) in the forums, but this interviewee is hesitant to do so as she does not want to "get a bad name" and appear as a whistle blower. Her suggested solution is to break the community into separate websites to parse apart the different sub communities on the website, but is hesitant to publicly discuss this in the forums as she wants to avoid acquiring a bad name in the forums and community.

Another interviewee, AF also refers to different types of Etsy.com users.

AF: I don't know about the popularity of crafting, but it seems a lot of people are coming out and showing what they can do, even just hobbyists. Like, maybe older ladies knitting. It's easier for them to show what they can do. And they have great stuff. Umm, I know a lot of people don't know about Etsy unless, you're online. So I don't know if it's made it popular or not. Its, ahhh, a lot of people don't know about Etsy. It's not like it's advertised that much outside the Etsy community. That could change, I don't know.

AF, similar to NG, refers here to a division between those on Etsy.com and those who don't know about it. I think this delineates the online crafting community and Etsy.com even more by separating it from those who aren't online. As shown in the previous statements, there are shared ideas of different groups and cultures within the online community based on what is made, why and how. 
In the following response, interviewee AG refers to the Etsy.com community as a

whole as somewhat separated from but integrated with a mainstream crafting culture (in addition to referring to subcommunities within the site). This response refers to geographical community, and how the larger online community can help an artist find a geographic location and community where there may be a better market for their art.

AG: Yeah, and too, when I said the outside community. You know how Emily did the thing on Martha Stewart. Which I think is really branching out towards the mainstream community, but at the same time, it's not Oprah. It's still in a craft area.

AG: I guess in some ways I almost take that for granted I think you tend to think of crafting as women centric anyway. Anything that is a community of women I think is fantastic and I think most women are going to feel that way. And you know I think that when you do read through forums sometimes its like you know its great its giving them um its just a hobby or just listing things or something they're talking about just the confidence they're getting from it... Other people if you enable them to have a different income while they are at home with the baby. So many different aspects. Some girls are just in high school and I think that's soo neat, to be still in school and realizing this was their way. You know when you're in college you can sell things or you know older women like our grandmothers that taught us to knit but are now putting their items up there and selling them, its just turned a lot of hobbyists into feeling like legitimate artists. And I think that's great because that's what they are. And if the only venue is a craft show, but you're reaching a much broader audience now. And for someone like me who questions their work, maybe the audience isn't immediately around you in your city or even your country. But there might be a really big audience for it elsewhere that now you're reaching.”

In the following quote, AG refers to popularity within the Etsy.com community, and how online notoriety relates to in person interactions. She is referring to herself and her friend, Emily Martin, whose Etsy.com shop is The Black Apple (mentioned in the literature review). The Black Apple is the highest selling and most visible Etsy.com shops - in both the Etsy community and in the mainstream media. Emily Martin has 
appeared on Martha Stewart and other more mainstream outlets such as The New York

Times, and is the poster child for a successful Etsy.com store.

AG: But I've had a couple people say, I think I saw you at Target and I'm like, how crazy did I look?... But she has a complete different level of following and people just interested in her life. Just from the comments alone. Everyone knows there's a readership on the blog. And I seem to have a lot more lurkers than people that flat out comment. And that's totally fine. She has a lot of people actively, actively interested in her life and commenting on it for good or for bad. I try to tell her. She says, you don't seem to get the, the, you know emails that I get. We both get a lot of for lack of a better word crazy emails and some of em are just not nice at all. And just don't treat you like you're a person and will call you out on things just because they think they can. And its just it's strange. We'll talk about that. She says you don't get the amount I do, and I say its hard being number one. You know,..... you are the Britney spears. You are under so much more scrutiny.

AG: But for her, going on Martha, that was a talking about going a little more mainstream. That was, it extra exploded after that and I think people who didn't know that community existed. Even though other Etsy people had been on, I think her specifically you know turned on people. It just you know became overwhelming.

AG compares the conflict her and Emily experience and compares it to Britney Spears a mainstream pop culture musician and icon. Emily, as she says, is number one - the most popular and visible community member both in and outside the community. This is similar to Spears in that in her popularity, she is known even to many of those who don't follow pop culture. In her popularity, similar to Spears, she is subjected to criticism and deals with “crazy emails and some of em are just not nice at all.” This type of relationship within the community between a "star" and their "fans" can really only be possible in a relatively large and impersonal community. For example, Britney Spears likely does not know most of her fans personally yet is subjected to scrutiny, similar to the Black Apple.

In this way, the Etsy.com community may be compared more to a mass media tool as it has grown in size. As RC described earlier, an artist may have to use journalistic 
methods to increase their business' visibility, similar as any company would have to navigate the media to sell a product. This indicates that the Etsy.com community has grown beyond a community of just crafters to a broader and more impersonal audience. This is due to a combination of Etsy.com being an online tool that makes geographic disparities obsolete, making the community larger in numbers and more impersonal as there is not necessarily a face or voice associated with a user/artist.

\section{Community Saturation}

Because the number of users on Etsy.com has grown to such large numbers, an issue arose that is referred to by some interviewees as "saturation.” The sheer number of people on Etsy.com has made it more difficult to be found and makes differentiation a goal for each of their businesses.

NG: Part of me is for inclusion but another part is also like, it's over saturated, everyone is getting a little greedy. And I don't know, I don't know if I've seen Etsy change because I haven't been in it that long, but I know it used to be like a few hundred or a thousand and now if you want people to see your stuff at all you have to post all the time and there are millions of kajillions of people. The bad stuff too is like Reading Frenzy now where you would go in the past to buy gifts is totally suffering. And now you can go online and order from anywhere and shipping isn't that expensive. I mean the online marketplace kinda sucks for local businesses and a handful of pasty internetheads who are all doing really well are selling like puff balls with googly eyes on Etsy.

AF: um, I don't know about the popularity of crafting, but it seems a lot of people are coming out and showing what they can do, even just hobbyists. Like, maybe older ladies knitting. It's easier for them to show what they can do. And they have great stuff. Umm, I know a lot of people don't know about Etsy unless, you're online. So I don't know if it's made it popular or not. Its, ahhh, a lot of people don't know about Etsy. It's not like it's advertised that much outside the Etsy community. that could change, I don't know. There are so many people on there now, it's just saturated.

Me: What do you mean by saturated? 
AF: There are just so many sellers. And um, people are loading new items every second. I know people who have looked for my stuff haven't been able to find it.

Me: Really. Why?

AF: If you search specifically for a name or a name that I have, um, an Etsy account for example. And then when you load your items, you have to, you have 14 different tags you can apply to that item so people can find it. It can be color, it can be size, if it's a card. So there are many things that come up under that color. I mean, it's like the world wide web, you know, you Google it, you put in a div tag and there are so many options.

Me: Yes, I can see it would be hard to differentiate yourself when it's that saturated.

AF: mmhmmm. So you have to be really savvy about what tags you put on your items. And I try to ask my buyers, how did you find me. And one time they found me on a blog I never heard of because someone stole the picture. Someone just did a post on gift tags and what ones had been loaded that day (on Etsy) and put a picture.

AG: But individual sellers you know, I think with the economy and it just, everyday there are so many more people. Luckily I feel established enough um where I feel like I won't get totally lost in the sea of artists, um. So for me personally the goal is to always have Etsy and I love Etsy but to have that as a jumping off point.

AG: I don't know about the site in general, because numbers seem to reflect its doing better than ever. But individual sellers you know, I think with the economy and it just, everyday there are so many more people. Luckily I feel established enough um where I feel like I won't get totally lost in the sea of artists.

Recently, additional community websites that are independent of Etsy.com have developed to create a space for more specific community for Etsy.com users. This makes a space for sub communities on Etsy.com to gather outside of the saturated Etsy.com website. One example is http://Etsyaoc.ning.com. This website was created using ning.com, a free community software. The website is titled "Etsy Artists of Color - a global village of minority artists and crafters.” This website features many of the same 
community areas Etsy.com does - a blog, forum, photo sharing, events, groups, chats, profile creation and so on. It is significant that a specific community on Etsy.com found it useful to create another website outside the Etsy.com site to congregate. Differentiation on both an individual and community level - on Etsy.com has become more difficult as the website has grown.

An advertisement (the website accepts Google ads) on the Etsy Artists of Color site (10.10.09) states "ETSY is very very big... Are your goods lost on page 3,565? List on ShopHandmade and get seen! ShopHandmade.com.” The existence of the Artists of Color site and its advertisements indicates the larger online crafting community is growing to the point where selling on Etsy.com requires one to be an "Etsy person” (or pasty internet head, as NG references them at one point) who spends a lot of their time on their computer just to have their goods found, as interviewee NG described. The role of computers in small independent businesses such as those Etsy.com sellers own will be discussed later in this section.

\section{Dealing with Conflict}

Another theme that emerged throughout interviews is how conflict is dealt with in the community. Because of the ability to share (and steal) ideas and information online is so great, issues arise in how to address situations when this occurs. The following statements describe the conflict and how community members personally address the issue. This first comment is a blog post from a craft blog maintained by a knitter who is heavily involved in the knitting blog/Ravelry.com/Etsy.com community. She addresses behavior across the community that she has observed. Instead of etiquette, which are 
generally accepted societal rules, online it is often referred to as "netiquette.” This

commentary is posted at http://www.flintknits.com/blog/?p=171 (accessed 11.16.09). ${ }^{3}$

(Please refer to the entire post text with reader comments in Appendix).

...Only nine conscientious, responsible stores** have honored my request that they get my permission to use the pattern for classes - which I granted, with some very reasonable terms. The rest of those stores, whether they realize it or not, are exploiting my labor and my free pattern to make a profit, without my consent.

The pattern is free for anyone to download and use and share. All I ask is that folks not use it for profit....My issue is not that I'm looking to make money off this pattern myself, though Jebus knows I could use it. There are a number of reasons why I chose not to charge for the FLS pattern...And, as much as I've been all "me me me" up to this point, it's not just me. There's a definite pattern of abuse when it comes to yarn stores using free online patterns for profit....I get that many LYSs are struggling to figure out how to negotiate the online craft world, particularly in an economic moment when luxury items like full-price yarn might no longer fit into many people’s budgets. Well, here's a primer: in Kate's words, "DON'T BE A JERK." In other words, don't do things online that you wouldn't do in the "real" world. Because the internets? ARE the real world. I am real. My labor is real. My intellectual property rights? Real. It's pretty simple: DON'T BE A JERK. ASK BEFORE YOU TAKE MY STUFF....If we treat each other like human beings instead of just businesses? Then local yarn stores can only benefit, can only earn better reputations for themselves, can only set themselves further apart from the JoAnns and the Michaels and the fucking Hobby Lobbies. Because then they make themselves an indispensable part of a respectful, personal, supportive local and global community, in a way that that JoAnn and Michael can never touch...

This post displays many of the themes I have seen emerge while studying this community, several of which will be discussed more in depth further on in the thesis as they fall into thematic categories. The aspect of this post that falls into this portion of the discussion is that it displays how the community deals with conflict, and similar patterns can be seen from the other interviewees. Flint Knits gives credit in her pattern to Elizabeth Zimmerman, the original author of the pattern she edited, as is usually the protocol when someone uses another person's pattern as a base for theirs. Generally 
credit is given to the artist in this (and other artistic) community(ies). She addresses the issue of those who don't give credit where it's due as a whole in the community - that it isn't just her problem, but something she sees often and is chastising those in the community who don't abide by this often unstated rule. As is typical with bloggers in this community, she says she is "posting this partly just to vent, and partly to bounce my thoughts of the internets [sic]," a common purpose for blogs, as described in the literature review. The end of the post asks "what are your expectations for the classes you take? Teachers, how do you navigate these issues in teaching classes?” She wraps up the post asking for feedback and trying to open up the discussion on the topic, making the communication optionally two way as opposed to a one way blog rant. Comments on this blog post are included in the Appendix.

Another element of her post that fits with themes that have emerged while observing the community is that while she points out the differences between the online and offline (in person) craft world, she also acknowledges that the online world is just as real: "I get that many LYSs are struggling to figure out how to negotiate the online craft world, particularly in an economic moment when luxury items like full-price yarn might no longer fit into many people’s budgets... In other words, don’t do things online that you wouldn't do in the "real” world. Because the internets? ARE the real world. I am real. My labor is real. My intellectual property rights? Real.” While norms and rules are different online, it is still a real world with accountability, she explains. And it can be challenging learning to navigate the online world. Like the real world, what levels of self disclosure and other details to share can be difficult to determine as the audience and rules online are different than offline. 
There are many similar scenarios of stolen creative work that arose across the

interviews. Interviewees addressed the issue in a similar way. They approached the

person with their issue, and acknowledged that generally the thief admitted to

wrongdoing and ceased.

AG: But just because someone who is doing it as a full time job has different needs than a person you know that's maybe just doing it as a hobby and I think, you know, right now I can't think of a major complaint I have with Etsy except that my big thing right now that I don't think they can is something about the copying that goes on. I don't know, they have one attorney and I don't expect them to totally you know. And I've had this experience, people I know have had this experience where people are literally printing off your work and tracing it. And then reselling it.

Me: Whoa!

AG: Yeah, that's frustrating. And their line is, yeah, yeah, it's oh well oh we'll follow anything if we're told by an attorney or the law. But doesn't common sense say I mean they've literally traced this. We have to write the people and say, everyone gets inspired by different people but when it comes to that point, you know, you need to remove these items. And this has happened to tons of people and I know Emily and I actually um, um are like coworkers because no one can understand this strange stuff we have and we'll always email shops back and forth, like look at this person, look at this person, they are. They think they're under the radar, but they're not. We'll get other emails from Etsy users which I think is so fantastic and so amazing that the community aspect of it that other people are watching out for you.

I am fascinated by people who do that that are willing to get so close. Its like, wouldn't you want to stay away from the person you're ripping off? But I've had that exact same experience and it's just horrible, it's horrible. Because you're not a mean person you don't want to say don't do this but its like, seriously, you need to stop. That's really frustrating. It's a strange thing. I've realized. At the beginning it was like, I don't want to offend this person, I don't want to hurt their feelings, but it's like wait! They're the ones doing this! Like, you know. I would just keep an email short as possible and say, I feel like, I understand inspiration comes from everywhere but when I feel like there is being some kind of copyright infringement which things are, implied copyrights, you know, I'm sure you understand that I'd need to take legal action. Or consider taking legal action, I've talked to my attorneys' about what this is. You know, remove it from your shop. And even if you don't have an attorney on retainer, I think most people get it, you know. Like, oh, you caught me. That I was doing that. 
Me: Or maybe they are at least embarrassed enough to back off.

AG: Exactly, exactly. 9 times out of 10 they'll back off.

This response is similar to the blog post discussed earlier in that it talks about the immediate anger one feels when realizing credit is not being given, but that the solution may be to simply say something to the person, call them out on it, and they likely acquiesce. “Ripping off” someone’s work (a pattern, a drawing, a character, etc.) from online may seem easier online than in person, as there often seems to be more anonymity online. People may not see each other face to face, talk, or even email but so much information can still be gathered online. And then if someone chooses to use this information to rip someone off, it may seem there are not consequences because the person online is not real (as the blogger earlier mentions - I am REAL, my work is REAL). Because this is a community however, there are repercussions - their thievery may be pointed out by another community member. Someone may point it out on their blog (like Flint Knits) or in a forum and call out certain people/businesses to get them to cooperate. Calling them out publicly appears to have worked in these instances.

\section{Data Type 2: Thematic categories}

The following section presents data that is organized into thematic categories, as opposed to data in the previous section that creates a description of the community, its members and their interactions. The following categories were determined based on recurring ideas and sentiments that arose in conversations with Etsy.com sellers. Each of the themes directly relates to how Etsy.com impacts the daily lives of these women. The 
effects on their daily lives are seen in many ways, from the amount of their income, to health care and how they spend their time. The themes include:

1. Women's work

2. Feminism and technology

3. Crafting and owning a business as a political statement

4. Legitimate business

5. Effects on local economy

Theme 1

It's weird that's what they do: Women's Work

As outlined in the literature review, what was and is considered women's work in modern society is often viewed as less culturally valuable than other work. Some consider craft to be particularly subordinate to art in its connection to everyday life and to women's lives. The interviewees' sentiments below exhibit the reclaiming of this type of work as a way to show its significance.

NG: People have been crafting forever and it's been like, oh its weird that's what they do, work at Michaels. But they put up a blog and it's like a brand new thing, like no one's thought of before and it's like guess what! I crochet! Or like macramé, I love macramé. And it's so awesome because it’s like this feminine art that is being embraced. Where before it was like, oh girls. But it used to be a thing where you had to do some kind of handicraft, like Jane Austen. And retire and you know, do your handicrafts. My mom tried to teach me how to knit when I was in grade school and I threw down the needles, like awww!

AG: Outside of people outside. I think there's a lot of different things. Some people are on the fringes you know. They kind of have a blog. And they're interested in crafts. But they haven't necessarily immersed themselves in trying to sell their stuff for a living. I think that you know the outside outside world, a lot of people just don't know about it. You know. Either you know about it, or you don't. And the people that I can relate to sometimes like $\{$ sic $\}$. One problem I 
have with Etsy and maybe they are changing this a little bit is you know, somewhere in the middle of them being, they were sort of people like me, and Emily Martin, the Black Apple, I feel like they were in some ways fantastic and they were giving us um, definitely kind of notoriety out there but I was kind of worried they (Etsy) were trying to sell the dream too hard. That, you know, do this and you can make a living out of it. And some people definitely can. I am extremely fortunate that I was one of em. But a lot of people aren't going to be able to. And Emily and I have talked about this too. We really wanted them to also seem to seek out more sellers than just buyers. Or just. Everyone wants the idea of oh I can live extreme, this is a super success story. But you know. You don't also wanna have people be let down and think it would take off right away.

AG: You know my answer to that was even if you're not making a living off Etsy... You can get a lot of visibility. Maybe it doesn't show up on Etsy but... and as far as the outside world, I don't know. I know that my friends that have absolutely no interest in the craft community they don't really understand what I do. And they're like, oh, A sells art for a living. They're kind of. They just don't get it. They don't get blogs... Its just it's just totally different. So I'll keep them in on what I'm doing. It's just a weird thing for me when people ask what I do for a living and I'm really tempted to like eh. I always just say I sell my art for a living. I can't bring myself to say artist just because that's my own personal weird thing. Or they say oh, so graphic design. Or oh, this. But there's definitely a thing I think people are amazed, I mean, not capitol A, but small time amazed that you can make a living selling your art you know and not have it.

$* * *$

RC: I have to switch gears a lot right now to make a good living. I do the work part time for insurance painting at Trader Joes. And the mural work at the theater. So that's a ton of work. And then I'm trading my chiropractor for two year's worth of visits and I'm building her signs. So that's like all my co payments paid for two years. You remember though, before I got the job at Trader Joes I was trying to go gung ho. But it coincided with Trader Joe’s which was crazy.

These three passages are insight into how three different artists, who use Etsy.com, make a living through their art and/or craft (or what may be thought of as women's work). The first passage describes the recent resurgence in this happening and the reclaiming of what is thought of as women's work by third wave feminists. The second two passages particularly address the significance of meshing income with women's work/crafting/art, two things that are not traditionally and paired together for 
women. AG hesitates to use the title "Artist” for herself and she describes having a difficult time explaining to others what she does for a living. RC's passage shows the effort involved in balancing several types of income to supplement an artist/crafter income in order to make a living. The difficulties in both making a living and then representing it to the "outside” world shows how what is thought of as women's work is not often viewed as culturally valuable compared to other types of employment. The issues pertaining to what is viewed as women's work and hobbies, including low compensation (low prices on Etsy), the lack of health insurance and benefits, and how to describe one's career to others are woven throughout the interviews.

Theme 2

I was a little out of touch with that computer thing: Feminism and Technology

The following interview excerpts give insight into the technological knowledge needed in order to partake in the Etsy.com community. The relationship between women, technology and income has historically been a problematic one. Etsy.com requires and creates an interesting skill set for women who partake in the community. The women are reclaiming crafting and women’s work as a political statement while developing and using skills that traditionally have been male dominated. For example, the math and graphing required for creating knitting patterns as mentioned in Flint Knits blog post may traditionally be considered masculine skills, but are also necessary in women’s work. Additionally, programming a website or webpage, online marketing, book keeping and other necessary business tasks may be deemed masculine. The following posts describe some of these necessary skills. 
AG: I was about 21, 22 and um, there I met my boyfriend, partner in crime, business partner and um he was, he had just moved back from New York and he was also self taught but knew so much technology and a Mac support person and ended up working at a design firm and doing lots of things, a lot of computer knowledge, a lot of art knowledge. So we thought, you know, we could collaborate but we didn't really know what do you do with that. So it just happened, that um, in June of 2006 I believe, or 2005 rather, is when Etsy started. So I wasn't really that computer savvy and wasn't that at all, I didn't have computers, mine broke, I hadn't replaced it. So I was a little out of touch with where the whole computer thing was going and technology and you know, there were blogs and different things. And I was in St. Louis and really feeling a lack of any sense of artistic community. Not that there is necessarily one there, but not what I was looking for. And Drew was like, you should look online so I discovered blogs and Etsy on the same night. I didn't really know either one existed and someone's blog mentioned Etsy so I became a member that night and so did Drew but we didn't list anything and then that was so that was Sept of 2005 and then it wasn't until. I listed a few things, a little bit of jewelry or a little stuffed creature of something. It wasn't anything. And then in March of 2006 so like 6 months later is when we listed the first print and um someone bought it and someone bought more and more and by that June, so within just 3 or 4 months, I was able to take a leave of absence from my work and I didn't have to go back, so it ended up just being a lot quicker in that respect than I ever would have thought that would have been.

AF: If you search specifically for a name or a name that I have, um, an Etsy account for example. And then when you load your items, you have to, you have 14 different tags you can apply to that item so people can find it. It can be color, it can be size, if it's a card. So there are many things that come up under that color. I mean, it's like the world wide web, you know, you Google it, you put in a div tag and there are so many options.

AF: So you have to be really savvy about what tags you put on your items. And I try to ask my buyers, how did you find me? And one time they found me on a blog I never heard of because someone stole the picture. Someone just did a post on gift tags and what ones had been loaded that day (on Etsy) and put a picture.

As discussed in the literature review, the relationship between women, technology

and income has historically been a problematic one. There appears to be several ways to look at the technological skills needed for Etsy.com. The first way to look at this is through Etsy.com specifically. The role of Etsy.com as a company that has spotted a 
business opportunity among this community itself is problematic as the organization likely has its bottom line and not the crafting community's wellbeing in its best interests. As RC mentioned in an earlier interview excerpt, several sections of the website (supplies and vintage) make it difficult for the crafters and artists to have their items found and subsequently sold through the website, but because those sections are such income providers for the company, they likely would not separate them from the main site. This means that more and more Etsy sellers spend their time trying to get their items found on Etsy.com than they do on creating the work itself. They spend more time on their computers performing other tasks than actually doing "women’s work," which in some cases was the initial intent behind starting the business.

This creates a heavier reliance on tech skills while less time is spent on the crafting/artistry itself. This of course also automatically excludes those that aren't technologically savvy (which is discussed in more depth later.) One solution to this problem can be seen in several community members (AG and The Black Apple, among many other seller profiles that are included on Etsy.com, in addition to Bread and Badger who are profiled below) are that the creative business began out of a woman's art and craft. As AG describes above, her partner set up her Etsy.com shop and maintains the blog and other technological aspects of the business, leaving her to focus on the art (which in itself is an interesting traditional gender role reversal - the female generates the core of the business while the male is in an administrative/support role). AG's set up of course is not a solution that works for everyone, as NG laments in an earlier interview she doesn't want to be an Etsy.com user that is on her computer all the time instead of interacting and working on her art. 
The isolation involved in relying solely on Etsy.com and other interactive technologies to market and sell art is another issue that arises from this technology. The isolation may be beneficial for some artists who don't care to interact on a face to face basis with potential clients, and they let the Internet sell their work for them. For others that were or are heavily involved in the in-person and local art and craft community however, this may have other effects (which will be discussed later as well).

More broadly, Etsy.com and other technologies can be looked at in a more positive light as the use of blogs, ecommerce and Etsy.com provide a way for women to use (almost) free technologies as a way to communicate with one another in order to create an alternative marketplace for their art and craft. This increases the ability to communicate regularly and across great distances while decoupling the association between women and technological weakness. As described earlier, other feminist movements succeeded in using technology and there are benefits associated with the increased communication new technological tools allow. A drawback, as outlined in the literature review, is the fragmenting of social movements (namely Feminism) once it moves online - inevitably some will be left behind as a result of not being “online” (this is exhibited in this community through the notion of the digital divide as outlined in the previous section). However, if crafting and making a living through it come from a privileged place, then the community being online may be appropriate. The community likely exists out of the reach of other women who are likely not online anyway, which points to the bigger issue of inclusiveness in the feminist movement. Second wave feminists are seen as exclusive due to a lack of acknowledgement of non white women. Socio-economic class, then, could be a criticism of this wave of feminists. 
Theme 3

A connection that has been lost in our mass-produced global economy: Crafting and Owning a Business as a Political Statement

One of the most prominent themes that is woven throughout the community is the political intent behind why individuals choose to partake in the community. From blog posts (Flint Knits) to interviewees and on Etsy.com itself, the reasons women have created and partake in this community are clearly expressed. The following several statements show a common anti-corporate sentiment among interviewees. They describe the freedom of having one's own business as opposed to working for someone else. This theme aligns with discussion in the literature review of making a living with one's own hands and creating things that could be bought cheaply at a strip mall as an activity that has a political intent.

AF: Because I could do what I like to do. And get to be more creative than I do in my job. I also get to set my own, whatever, hours, or whatever you call it. I know that its, it's just another type of freedom, having your own business even though it is more work. You know, it's just something that suits me better.

AF: I've had so many corporate jobs where they decide everything and it's really hard to find inspiration. (laughs) I've been trained in that environment and it's just what's driving me...

$\mathrm{RC}$ : I think the connection between the maker and the consumer is important, a connection that has been lost in our mass-produced global economy. There is a reciprocal joy in this kind of work that is also very fulfilling on both sides. It is my hope that my work brings inspiration and happiness to my clients while striving to make very little impact on the environment.

RC: I think that because something that is made in China or is in Wal Mart or something, you just assume that a machine totally made it and it's just kind of chemically. And yeah a person probably could've made it or makes a lot of that stuff in a sweat shop, but it just doesn't have.... When you actually meet the 
person who made something, it harkens back to how it used to be before everything got so crazy, like the economy and all the crap made in these factories. When it gets more back to a sustainable way, back to how it used to be and just it feels one hundred million times better. You won't feel bad spending your money on something you need because it's not going to a corporation. I mean, it kind of depends on the supplies and stuff, but it's just the fact that it's not going to a big nasty corporation and it just makes you feel so much better.

Me: What is bad about your money going towards a corporation?

RC: It just seems it's gotten so out of control. They live above the law and control everything. It's depressing.

RC: Well like not just like how many owl things can one person buy, but how many can one make, dude? You know? I mean, I'm sick of making the same thing. And making my stuff and I feel bad because it's my stuff, but...

RC: Just in the fact of buying a huge box of stuff that comes from china. Some stuff you just don't really know about where it came from. Which is why I'm focusing more on this mural thing and doing more community stuff. I mean, (business name) I did just to survive. I had to learn to let my artwork go. Because you get kind of attached to it, and having to start turning it out and sell it constantly, its kind of a hard leap. So at least with the soft stuff, it's like there's thousand stuff out there that I made.

This sentiment about the local and the global is echoed in the blog post in the above discussion on conflict resolution in the community (Flint Knits). The political approach behind this crafter and the community in general can be seen intertwined throughout this and many other blog posts. Flint Knits says "Finally, and most importantly, I believe that Sharing is better than Capitalism and indie is better than corporate - which is why I love local yarn stores, and is also why it fills me with livid, unholy fury to see these businesses profiting from my free work without my consent. I want to support local yarn stores. And I know that classes are an important way for them to sell yarn and to get folks in the door. Because of this, whenever an independent yarn shop has contacted me and asked to use my pattern for a class, I’ve always said yes, 
provided they give me credit for my work.” This political bent can be seen in the fact that often patterns are posted for free (as long as credit is given to the original artist) because knitting is seen as something that everyone can do, as a designer using someone else's pattern as a base, you are just “execute(ing) some basic math and writ(ing) down some simple instructions” (Flint Knits). Knitting is seen as a communal knowledge, not something that has to be commoditized and paid for.

Flint Knits also calls out labor/women’s labor, its relation to the politics and particularly how it pertains to e-commerce. "In other words, don’t do things online that you wouldn't do in the "real” world. Because the internets? ARE the real world. I am real. My labor is real. My intellectual property rights? Real.” This quote particularly expresses the tightly intertwined themes that arise in this community. It expresses that labor and income are thoroughly political and a result of how society values that labor, and that there is a digital divide that is involved in this. In this arts and crafts community, the issues of women’s labor and intellectual property (IP) rights are particularly prevalent. There are issues of people not respecting IP in the online arts and crafts community and on Etsy.com particularly - hence the section on how conflict is dealt with in the community. Flint Knits explicitly calls out violators who don’t respect or acknowledge IP, labor and the Internet as “real.”

Another commonality that arose among interviewees and in Etsy.com profiles on their website is the concept of owning a craft business as a positive alternative to a traditional nine to five job. In many cases, consciously choosing to not partake in traditional nine to five employment by creating one’s own business is a deliberate 
political statement. These business owners also struggle against strong notions of what a legitimate job and business are, which is discussed further on.

The passage below is an excerpt from a profile of an Etsy seller that is posted by Etsy on Etsy.com. Etsy conducts and posts these interviews regularly in their seller spotlight section where they profile and try to personalize the many, many sellers on Etsy.com. The interviewee's responses outline the perceived benefits of working for oneself, owning one's own business, and selling on Etsy.com. This interview is an example of what AG complains about - that Etsy is "selling the dream" too hard. Refer to a for entire interview (source: http://www.Etsy.com/storque/spotlight/quit-your-day-jobbreadandbadger-3650/):

I've been looking forward to bringing you the story of Amanda and her significant other, Sean, who have both been able to quit their day jobs in order to successfully earn a living running their Etsy shop, BreadandBadger. Soon after Amanda quit her day job the budding success of her glass business presented a similar opportunity for Sean to help her run the show.

How did you originally get into the business of making things?

I've actually been trying to find a way to make a living with my artwork my whole life! It's just one of those things I knew I was born to do, without a doubt. I remember selling art in high school to my friends, like t-shirts that I'd drawn on with puff-paint. I've gone through a number of phases and false-starts (tattoo artist, children's book illustrator, web comic creator, beaded jewelry designer/lost-wax caster) before finding a hit with etched glass. Sean had been scheming to work for himself for a while, but neither of us ever thought he'd be working for me! It was a bit of a surprise, the way it happened.

When you first started selling on Etsy, did you have dreams or goals of eventually quitting your day job?

I actually quit my full-time job before officially starting my business back in 2005. I just couldn't handle working in a retail store while I was trying to draw a web comic and learn about business. I opened my first Etsy shop, SilverSquirrel, in 2006, but it never really took off - mostly because my heart wasn't really in it. I had to get a part-time job shortly after, but I was lucky enough to get a gig working for a local designer who worked with vintage accessories, so I learned a lot about business from her. I experimented with other art mediums, read lots of books on business and marketing, and basically absorbed everything I could. I opened BreadandBadger in the summer of 2007 and dove right in — I finally felt 
confident about my new glass products. I only had this shop for about two months before it needed my full attention, but I'd been doing craft fairs and promotion for a while before that.

When Sean quit his full time job last fall, it was completely out of necessity. I was so swamped with orders that I basically had to hire someone to help me, so there wasn't much to think about. We bought equipment so we could start production work — I had been hand-engraving each item before that. ${ }^{4}$

The following passage from interview RC also reflects a preference for finding an alternative route within the "real world."

RC: I think that. Well I guess maybe I can't speak for anyone but myself. But when you're growing up. They push you. You gotta go to college. So its like a lot of people do end up going to college and go through the whole role there and they get out and are like, now what? I have a liberal arts degree? Okay..... it was all fun but you had no taste of the real world and you get flung in there and are like, uhhh okay what do I do now? So I think a lot of people who are creative are like, I'm going to start making stuff because I don't want to work for some corporation doing stuff I don't want to do. Its like I might as well just try and do what I love, put it out there, and with the right tools that have been popping up like Etsy, and the craft fairs getting organized, people really started making better money doing it. So they don't have to go work for a corporation.

The interviews conducted by Etsy.com have many attributes that are similar to those I conducted by phone and in person. The seller gives a history of why they chose to make a living selling their art, and it involves a history of being unhappy in a traditional nine to five job. A nine-to-five job may be viewed as typically what is better compensated (through regular income and benefits) and thus more culturally valuable work. This is also a perfect example of what AG called Etsy.com pushing the quitting your day job. AG commented in the interview that Etsy.com began using her and other sellers (like Bread and Badger) as examples of Cinderella stories, where there is an ideal of quitting a day job to pursue the crafter's ideal lifestyle of making a living 100 percent from crafting. AG quickly pointed out that there probably just is not enough room on Etsy.com for this to happen. Additionally, the shop owners' profiles Etsy.com profiles are 
those of young, usually unmarried, childless couples, leaving out single women with

children, who could most benefit from an alternative work schedule outside the nine to

five. The profiles do usually have a woman artist/crafter whose male partner does the "business" side of things.

Theme 4

What are you, a business woman? Legitimate Business

A recurring sentiment that arose in interviews is how the women's work is viewed by themselves and others. Some interviewees, such as RC and NG, are more comfortable with calling themselves artists, whereas others like AG are more comfortable calling themselves small business owners and prefer to say they “sell art” instead of calling herself an artist. Regardless of how they refer to themselves, all the interviewees addressed the benefits and challenges of being business owners. These excerpts address the question: what is a legitimate business and how does a legitimate business owner act? The following comments from AG occur at different places throughout her interview.

AG: And I think sometimes I've noted in my line of people's art/craft thing, that there's a bit of a disconnect with customer service. They want to, they make a great product but they'll be like I forgot to ship it a month later. And its like, is it a business or is it not? From a very early time. Even when it wasn't our full time business it was still a business. I still write ever single sale that I have. You know about, when your print will ship. When this will happen... The joke sometimes is that it feels like online waiting tables, you really have to be on it. It makes people come back for more. And you don't know who you're selling to. You could be selling to the person of such and such company you know. Or such and such. They could be, it was a really positive experience for me and they like the art work, I bet they could handle an illustration job. And the bottom line is treat every sale likes it's your own money being spent. You know. How sturdy would you like that packaging. And I think that, or I like to think that, more than anything, um, and hopefully you know people relate to the imagery and stuff like that but beyond just liking the artwork there are other elements. 
AG: Our sales have been really really steady. My joke is Emily, you're recession proof. And like I said 99\% of people I know doing this are really struggling and I keep thinking its just getting through 2009, maybe that is it. And you start to have an appreciation for what you take for granted. Like, oh our artwork. Paid for the rent this month, paid for that TV. Or bed or whatever. And it's kind of, when you think about it it's neat. And the thing about Portland is health insurance is more expensive. And my thing is that if I was going to be a legitimate business, I wanted health insurance for the first time in my life. And that was a very conscious decision. And that was another thing that is an attack in the forums. A couple years ago, when I was 25 , some woman was like, if you want to live like a 25 year old and rent an apartment and have thrift store stuff, then I guess Etsy is a living. And it's like that's such a weird comment. I think a lot of people are in that situation, not just 25 year olds. And so it was like, if I had all the money in the world, I don't know if I wouldn't be thrifty and I think I always would. It was just a different take on that.

AG: I'm certainly in it to make a living, and I think it's hard when people are open about... I don't have the secret. If I didn't want to pay my bills with it, I would probably do different art but if I wanted to make an amazing living, I probably wouldn't be doing this. It's about choices and I love being self employed. I didn't know how it was going to happen, but I wanted it. And that's important to me. My time has more value to me in more ways than other things. I'd rather have the choice to be outside today than drive a brand new car... And when I give people a canned response, they say, what are you, a business woman? And, it's like exactly. Selling art is my business. That's a weird attack on treating. There's that weird kind of back lash from treating things like a business that you want to be a business. So it's not like in its pure form, I don't know. I don't quite understand where that attitude comes from. Where people want to buy from an individual and a person but then also expect you to have a corporation like target, where they treat you like, the next day, why hasn't something arrived? And its like I ship twice a week and I try to get their item a week. But if someone literally writes the next day, its like, it's physically not possible to get it there that quick. It's those sort of things. Like I'm still a person. But in a very long time. I think that weird middle period of Etsy. Like in the beginning it wasn't like that, but then a year ago or so there was a lot of weirdness like that. But it's resettled again where I feel like I haven't shaken my fist at an email in a very long time. Maybe there just hasn't been a recent flush of new Etsy users.

AG: I don't think we as users get quite as much information, but I think what we get is a little more relevant than it used to be. The changes that they made, the little tweaks, the things like that. It still puts me in a scary spot, I mean the 40 million dollars, the new CEO, you know, I met Rob in person, I don't know Maria, if she is as in touch with the other users, but you know, so far so good. I don't know what the future will hold but no one does. It's probably not a good 
idea to have all your eggs in one basket in terms of Etsy. And it's very easy to let that be your everything and I'm trying. Especially when the sales are rolling in and you're just like, well, I just don't have time to kind of track down other places to get my money from. But we've made a very conscious effort to look for other things. Where if Etsy closes down or if something happens, then we're not completely unemployed. That we're established because that would be scary.

AG's comments display the interviewee's struggles with becoming a legitimate and established business and defining what a legitimate business is. While some view the ability for women to make a living from their handcrafting, the experience of it as described by AG is quite different. It feels like waiting tables, or a blue collar job, she says. One major part of how the business owners see themselves is how customers and others treat the business owner. Even though this is a small business, AG describes scenarios where customers expect overnight turnaround as if the business were Target or another large corporation. Even though they are a small business of one or two people, they are expected to respond as if they have the resources of a large business. The professionalism of Etsy.com may contribute to this - it can be hard to tell many details about the small businesses on there when their web pages all look exactly the same. The products of course differentiate them, but buyers often are looking for a certain product so are looking at page after page of similar products and remembering which seller a product was made by can be difficult. To some, the products can look like they come from Etsy.com, not a specific seller.

The amount of income, absence of health insurance, potential for non traditional hours and working from home as opposed to an office also adds to a lack of legitimacy for some of these business owners. Sometimes the definition of a legitimate business comes from one's own socialization, and sometimes others - NG refers to a comment a 
woman made to her about not wanting to thrift for clothes after age 25. And throughout the interviews, there is a hesitancy - in one spot, an interviewee says “yes, I’m a businesswoman" but elsewhere tells of her hesitancy to call herself an artist as her friends don't really understand what she does. "Businesswoman” may seem more respectable or adult-sounding than "Artist” and earn more respect in some social situations.

The following passages address the financial concerns and responsibilities of being what some may call a legitimate business owner, including the challenges around dealing with taxes, pricing, and marketing.

RC: The thing about that is hopefully word doesn't get out about that. It's the whole punk thing in regard to that - oh well, I'm not going to pay taxes to some government that I hate. After seeing that black money thing on Frontline, I don't feel bad about not paying money. Just government stuff, and cleaning money and bribing, and deals with Saudi's. Crazy corrupt men basically running everything. And you're thinking, I'm just this tiny little fish just trying to make it, making this stuff, trying to survive, you know. I just don't want to be a part of it at all. I don't want to, every time I hear the news I get angry. I'd just rather be more off the grid, working from home. But the internet is kind of the system though in using the system to beat the system. I think that in the next couple years, there will be a government crackdown and they'll start requiring social security numbers and maybe Etsy would send everyone a 1099. And you'd have to report otherwise it would flag in the system. Or PayPal, they would crack down on PayPal. But it's like cracking down on the little guy and when you realize how bad the government really is....its like, fuck you, crack down on your fuckin self. (laughs) That's where all the billions and trillions went you asshole, don't take my hundreds.

NG: The thing I like about Etsy over stores is that I don't like things to be to expensive. Like if I make a sock monkey, I would like to get $\$ 20$ for that sock monkey at least. Whereas if I sell it to a store, I can sell it for $\$ 40$ because they are going to mark it up to get their percentage. And I don't want anyone to pay $\$ 40$ for a sock monkey. And I know people that will, but I don’t have money for that, but I can buy a $\$ 20$ sock monkey.

AF: Yes, if you are continuously making things. And you have to have very good pricing too. Etsy is definitely cheaper than if you go to the stationary store. These things are more handmade, they should cost more because of the effort, but they can’t really charge a whole lot. But it’s cool. 
AF: Well first of all, its that's the way it is on Etsy, most things are underpriced, it's so competitive. But, um, I think too because it's online you don't have a lot of overhead, so you can sell more and the more you sell the more you get. Which is a pretty good deal, it's not something that will make you rich, you know what I mean? I'd have to do a lot more. But it's just a beginning, it's really fun because it's like a store, and you have to run it like one. Like you would a regular store. And it's really easy.

These comments above show the various ways Etsy.com affects the community and individuals financially. As previously discussed, Etsy.com has provided numerous artists and crafters with a larger audience to sell their wares to, and provides a larger geographic pool for the community. This has allowed artists and crafters with a new venue to sell their work that is 24-7 and geographically much larger than if they operated solely through local craft fairs. Etsy.com has capitalized on the increasing popularity in handcrafting and helped build momentum for the handcrafting movement, building a market for sellers and providing huge amounts of visibility and awareness for these types of businesses. In this way, it has provided a new source of income and thus lifestyle for artists and crafters.

Some of the interview sentiments show positive and negative repercussions to this. As AG outlines, there is a possibility that one can become entirely reliant on Etsy.com for income, making your business subject to the repercussions of business decisions made by Etsy.com executives that you have no say in. Additionally, as RC explains, many of the businesses are cottage businesses, where income isn't reported to the IRS. Etsy.com however keeps track of sales and income for buyers which could jeopardize sellers who operate this way. NG also starts to describe Etsy.com's effect on the in-person community, such as the amount, size and profitability of art and craft fairs 
(this will be discussed in the next section as well). Many interviewees commented on how low prices are on Etsy.com compared to art and craft shows as the website has become more saturated. Due to the many types of sellers (hobby versus sole income), some sellers drive costs down by providing competition.

Theme 5

People where I am kinda get what I’m doing: Effects on Local Economy

Of the interviewees in this study, RC and NG are the most active in their local craft communities, and using Etsy.com supplements the sales and income they get from in-person events and selling in local boutiques. Both interviewees mentioned they prefer to not spend the majority of their time on the computer jockeying for visibility on Etsy.com. Both of them however live in cities with relatively active art and craft communities. AG however mentions the lack of community where she lived and so is more heavily involved in the online community. She moved to Portland, Oregon to live in a city with a more vibrant arts scene. AF lives in a city with a craft community that she dabbles in, but does not fully partake in. The comments below illustrate how place and community - both on line and in person - affect the artists' lives and business decisions. Place/employment/income

The first theme within how local economy and Etsy are connected has to do with place and selling their work/employment/income. This first passage shows how Etsy allowed AG to sell outside of where she was living and how this generates an income for her despite living far from where her customer base is. 
AG: The sales were strictly almost. I mean, they were in the middle of the country but they were so usually to New York, to California or out of the country and so it was weird because you could tell, or to know that the place you were in. Not all the people there, but the shop owners, or the people you know, a lot of their money isn't going to, there aren't a lot of local artist prints for sale. You know. And you still don't see that. And so that was, it was interesting to feel like. I know people where I am, kinda get what we're doing. It was a strange thing to explain. And I don't mean this to sound condescending, that the people in St. Louis are naïve in any means, but um, just you know, in terms of, its just very different living here in Portland it's a very, very different scene. That you walk into shops and so many artists are represented. There are so many places to buy artwork and and it's just not the case there.

AG: It really worked for me because a lot of artists I think don't love what they do and I certainly don't either so I don't know if I have the in person confidence to really sell my work and say here I think this is good, buy this. Cuz I don't know that I do think that so my thing is that it's a really great almost passive way of selling it. You know, they're taking a very low percentage, you know, after coming from the jewelry thing and talking to people, and do you want to buy this, and it's the stores and it's 50/50 and you've done so much work and they can't sell it for this amount, you know it was great selling with Etsy. You are so in control of it you are in control of your content and you know. If someone didn't like it you don't really know and if someone did you get positive feedback. So it was a very passive helpful way of starting something.

The following comment by NG shows how the growth of the craft community and the involvement of larger companies in the indie business community affect the small indie businesses. NG below laments how a larger, more corporate national craft fair edged out a smaller community-based one.

NG: It's weird, because when I first moved here there was the Handmade Bazaar, which was started in my friend's back yard. And it was one of the first DIY craft fairs. At least in Portland. I think in America. I mean just like the fact that like there were Christmas bazaars, but I mean in terms of young weird people just making stuff and selling it to each other. But I think of Internet people as weird people who just shut ins who talk to each other on the Internet all day. Who now have been coming out more and more after Etsy and after craft has become a little more mainstream. There are some really random people now at craft fairs. Before it would be like your friend who made DIY crafts and there are people who sell weird expensive perfume lines or like travel packages on the side and have really fancy, I don't know. The craft thing, I think based on Etsy is that even the handmade bizarre got priced out of the Wonder Ballroom I think last year. The 
year before they had their Wonder Ball room for their thing. And they've been doing this every year for 7 years. At least. And the Renegade Craft Fair, or whatever one is really really big, it was in Seattle. They were like, oh, well they're like a corporate craft fair now they're so big, and they were like oh we're going to have to do one in Portland now because Portland is so crafty. So they came down and they offered the Wonder Ballroom more money or something, and took out huge ads and like kinda just monopolized and Handmade Bazaar was just like forget it and Wonder Ballroom said sorry and I know we offered you this weekend, but now its taken, they offered us more money. And the Handmade Bazaar couldn't do it there so these like corporate craft fairs so are generally from the Internet like all nerdy crafters and its just been getting bigger and bigger where its like the grassroots, human in person thing that's been going on in Portland for forever is just getting kind of pushed to the margins.

NG here indicates that the corporate craft fairs that edge out smaller ones are often from the Internet. She points to how the community has changed - that there are more elite, expensive products for sale and that it has grown so much larger thanks to the Internet and websites like Etsy. Indeed, many Etsy sellers also sell at Renegade Craft Fairs nationwide, including interviewee RC and the aforementioned number one Etsy seller The Black Apple. These fairs are large and draw from large geographic areas for sellers and buyers. Shows are now in San Francisco, Chicago, New York, and Los Angeles. NG describes how in Portland, large craft fairs like this have pushed smaller local ones out of business. The passages below, also from the interview with NG, describe how she sees online tools affecting local economy.

NG: Part of me is for inclusion but another part is also like, it's over saturated, everyone is getting a little greedy. And I don't know, I don't know if I've seen Etsy change because I haven't been in it that long, but I know it used to be like a few hundred or a thousand and now if you want people to see your stuff at all you have to post all the time and there are millions of kajillions of people. The bad stuff too is like Reading Frenzy now where you would go in the past to buy gifts is totally suffering. And now you can go online and order from anywhere and shipping isn't that expensive. I mean the online marketplace kinda sucks for local businesses and a handful of pasty internetheads who are all doing really well are selling like puff balls with googly eyes on Etsy. 
NG: You know that antique high you get when you're out thrifting and you're just on and you're finding all these wonderful treasures. You don't get that on Ebay when you're just finding everything with the word flower on it. You just get like, an Internet halo. But I feel like I mean I like Etsy and I don’t like. More people probably do buy my stuff than if it were just posted on my website. But at the same time I want people to support their local economy.

Partially involved in Etsy

This passage by AF displays that one can start small on Etsy and not jump entirely into handcrafting for a livelihood. In this way, it encourages more individuals to partake in the community, because it allows people to dabble in selling their handmade wares without giving up a main job entirely. I find it significant as well that she refers to selling one item at a time as “just in time inventory.” She has worked for large manufacturers and compares her inventory system to that of large corporations she has worked for.

AF: yeah, I would definitely get a website together but I would probably start at, what do you call, art and craft shows locally. I would probably do something like that and ask boutiques if they would sell some of my cards. But the nice thing about Etsy is that you can see what other people are doing and it gets you inspired to learn new things. And prices are competitive.

Me: And it's probably a good way to dip your toe in if you work.

AF: Yes exactly. You work on it at night and post as you can but to be in a show, you have to have a lot of inventory. On Etsy, you can get away with having one item ready at a time and depending on how busy you get, it's more like just in time inventory system.

The following passages also show how Etsy allows for testing the waters of the community on one's own time and terms, without the commitment of building a large inventory, registering for a craft show, setting up a booth and investing a weekend in order to see work in the in-person community. 
AF: I SEE lots of stuff I'd like to buy, but just haven't. I will. I haven't taken the plunge yet. There is nothing that is keeping me from doing it, I'm just busy. I'm on the computer a lot and try not to be on the computer as much. So with markets, I have to say that when I go to them, I tend to buy something there. I don't plan to, but I come home with something. It could be ceramics, it could be you know, cards, it could be anything. So I think, I think it's a good combination to do both. $* * *$

Me: And how long before you were on Etsy were you making these items and how were you selling them before Etsy?

NG: Ohh, um. I quickly feel sad about my local economy. Well I guess I'm still doing it locally. I've been making sock monkeys maybe 7 or 8 years, and making zines and comic books about 15 years. And I usually sell zines and comics in stores locally........

Sock monkeys I sell at like handmade bazaar and some I sell at reading frenzy or like local craft fairs. Um and I sell some things on my website but its not as attractive as Etsy or anything like that. So now I sell them on Etsy. And I also sell prints on Etsy and I don't sell those anywhere but Etsy.

NG: A lot of it is, well I still go to the local things but I make more money selling on Etsy. Like I make a calendar every year and I sell that on Etsy. Um, I sell just as many calendars if not more in the stores but then since I started having a more active Etsy page last year, I sold at least 100 calendars on Etsy. So both. Where other things like pet portraits sell through my website.

NG: The internet is how I found out about zines and got into mail order with them, so that's good. I think that if you live somewhere like St. Louis you could maybe have an Etsy meet up.

AG: But it is a good thing that if you're kind of shy you can still put your stuff out there. Or if you're in the middle of nowhere. And we have some super talented friends in St. Louis and I'm like, please, please get your stuff on Etsy, get it out there. And they still haven't but it would be so great for them.

Etsy’s business decisions affect the handcrafters’ businesses

Of all the interviewees, participant AG has the closest relationship with Etsy management. Her excerpts below show how Etsy’s business decisions affect her decision and how she chooses to partake in Etsy and the handcrafting community outside of Etsy. 
Other interviewees as well commented on the Etsy's business decisions and their

opinions of how they should steer and organize the business.

AG: And they definitely have some um employee shift. And to be completely frank I was really worried about Etsy about 2 years ago or so. I feel like they were hiring and hiring and hiring and hiring so many employees and no one it seemed from the outside that no one had distinct roles. It was like, I know this friend, come work here. Not that that's not how a lot of jobs work. I was just like please do that in a way that still keeps you know the mission of Etsy clear. That it's still an online community. And they started doing so many in person things. But so many of us are not in New York. Like it seemed like, I don't know the number, but like 20 full time employees just makin the stuff for like craft bags. And its like, that's a great idea in concept but you know, and it's a handmade site, but sometimes I mean that seems like what that means with money and like major flaws in the site that need like to change. Like the engineering things. And I mean, they did have a new guy from yahoo. And since the new CEO happened there's been a lot. Super personal, you know with the employees. But that's fine with me because they're also fixing very evident small flaws that needed to be done. Little things from like when you relist an item like there's no reason when people have been asking for years. When you relist an item, have it automatically go back to the categories that it was in. You know, save yourself a step. Its stuff like that that was like, do those things. So apparently stuff like that is changing. And another thing is Rob was really young. I don't think he knew it was going to explode like it did and it's amazing that it did. And it's definitely going to have growing pains. And you know I feel like everyone can do a blog. They made a lot of mistakes that are quite clear but at the same time its even just amazing the opportunity it presented to people. And I feel like well criticism at the end of every sentence but I still appreciate it. But when I go through the forums I don't really contribute to the forums except that one time they were trying to fix that big getting rid of digital prints. And I definitely got in the forums then. When I see big mistakes. Or when they were trying to draw up an Etsy constitution which was oh, just the worst thing ever. And I think that they definitely learned from that.

Me: With the forums, they will talk about what they will do and chime in?

AG: That used to be it and there still is and they still encourage discussion but I think the discussion previously you know, one of the um admins will start a thread and people would you know just. Now they have a little bit more of a pool where someone will post but those tend to be closed, its just announcements. And I'm fine with that. I don't need to read through 70 pages of things. And then they'll point to another post where you can discuss it, so it's definitely open to feedback from the community and I think it has made major changes. But you know I don't know if they need to be quite as open because how can you when 
you have millions of users with very different needs. But you know I don't know if they need to be quite as open because how can you when you have millions of users with very different needs. You know someone. That's my big thing. I think they should have an Etsy summit where they invite people that do this as their full time job, some new people, people who are just enthusiasts. Whatever just to hear more feedback without that fighting. Because it seems to turn to. There's this tone on the internet. Everyone misinterprets people's tone. It becomes this fight between people instead of back to the main issue. Which is just kind of a reason why I prefer staying out of them. But just because someone who is doing it as a full time job has different needs than a person you know that's maybe just doing it as a hobby and I think you know right now I can't think of a major complaint I have with Etsy except that my big thing right now that I don't think they can is something about the copying that goes on. I don't know, they have one attorney and I don't expect them to totally you know. And I've had this experience, people I know have had this experience where people are literally printing off your work and tracing it. And then reselling it.

\section{$* * *$}

RC: You see A LOT of that - scrapbook prepackaged materials. And it gets annoying too because it really clogs up the system. And like the other thing that clogs up the system is their whole vintage thing. And they are like adamantly all about that... So like keep it, but maybe make another site for it, like Etsy vintage and Etsy supplies... Cuz its cool to have it, it is like a whole online super store full of cool stuff, but then its just gotten so big, that its like, each one could stand on its own

Etsy driving in-person community and local economy

The following passages show how Etsy interacts with and in some cases enhances

the in-person community where artists live and work.

RC: I think a lot of people find me through my label and a lot randomly through Etsy. I get a lot of first time buyers on Etsy. The theory I have about that is that people see my work or out in public or a friend has something and they go to rosybird.com and they have to log in to Etsy. I'll see that they just joined and then bought something from me.

Me: So artwork is driving people to Etsy?

RC: Its both. If Etsy had a little box you clicked as you were purchasing you could hone in on how people found you. But not a lot of people are going to randomly tell you. But some people will send you a message and say, I saw you at a show, or my friend had something. I get a lot of people outright contacting me that probably saw it someone or saw it at a show. 
Me: What do you think the craft community would look like without Etsy? How do you think it would be different without it there?

RC: It would be a huge loss. Obviously it would be hard to imagine not having it. Because that's how you sustain your business. Like at a craft show, you make a bunch of money and sell a bunch of stuff, but it's just that one day and you're depending on that one day that one crowd. And then Etsy is like a 24 hour world wide selling machine for you it would be like just a huge chunk of your business would just not be there. So people would probably have to be doing tons more shows.

Me: So do you think it's affected the shows that go on?

RC: um, no. I think if anything it promotes them better. A lot of people will go on my website (Etsy site) and see what shows I'm at and come see me. And then that will lead to maybe they'll buy from me, but also from other people. It's all about just reaching people. Like if anything I think it's totally made it grown. And shows are just more social and it's like a social thing with your friends. Its not like a chore like, not like online shopping is a chore but sometimes you're like on a mission and I just gotta go and get some this this or this. But a craft fair is like it's just going to be fun, so go check it out. You meet the artist which is a huge thing. And then. Every body that's there and then, drinking beer, you know. Music. Crafty fun things. And people who aren't super crafty but want to be, they can stick their feet in and try a work shop or buy a kit and go home and make something.

The two following passages are excerpts from two different blogger’s blogs that also show how the online community creates in-person relationships. The bloggers met others online and eventually met up “IRL” (in real life).

Crimson Purl (blogger): Then I happened to look up from my needles and seated right across from me was a blogger pal that I had yet to meet IRL! (http://crimsonpurl.blogspot.com/2009/06/tippy-toe-knitting.html )

Blair Peter (blogger): Finally meeting Maria, after talking to her online for such a long time (years? in a way that's true) was great. It was so much fun to share such a special evening with Maria and Stephanie. It makes me all mushy and happy about this whole blogging community we share. (http://blairpeter.typepad.com/weblog/2008/10/portland-i-shou.html) 
In the first two passages of this Local Economy section, the interviewees both express that they would likely be more involved in the in person craft community if it weren't for Etsy.com. In AG's case, she says there wasn't a community to find in St. Louis, MO and that she discovered it through Etsy.com. The people she met through Etsy.com (The Black Apple and others) and community she found pulled her to Portland, OR where there is more of a community (although she doesn't sell in the in person community in Portland). AF says she would sell in person if there were no Etsy.com and that she would develop her own website. In these two examples, Etsy has both helped individuals discover the community but also possibly inhibits participation in local, in person community. The opposite is true for these specific blogger's passages - meeting online drove them to meet up in person. 


\section{Chapter IV: Discussion and Conclusion}

\section{Discussion}

As outlined earlier, the purpose of this study is to understand how women in the handcrafting community use community websites such as Esty.com. More specifically, I am curious what role technology, and Etsy.com in particular, plays in the lives of women who are a part of this subculture. As can be seen from the above data, women use Etsy.com and other technologies for many different purposes. For some it is their primary income, for others it is supplemental. In some cases it pulls individuals away from inperson interactions, and for others it plugged them into an in-person community of likeminded individuals. The impact of Etsy.com on these women's lives is diverse and far reaching. By affecting their income, how much time they spend on a computer, how much time they spend inside and outside the home, their working conditions (in an office or the home) and flexibility of their schedules, their daily lives are significantly altered by the use Etsy.com and other online tools. The many ways their lives are different revolve around the themes that emerged throughout the interviews, including:

Women's work

Feminism and technology

Crafting and owning a business as a political statement

Legitimate business

Effects on local economy

The themes, as seen throughout their statements above, are intertwined within each passage, and all relate to the daily lives of those women who partake in the community. For example, the theme of feminism and technology (as evidenced by the 
women’s technical capabilities in administrating their businesses) is closely related to owning a business as a political statement. While owning the business is a choice to go against the mainstream, using Etsy.com forces participants to spend more time on the computer differentiating themselves from other sellers (requiring technological skills) instead of working on their craft or other parts of their business (reclaiming women's work). Choosing to use Etsy.com and using the technological skills also affects their participation in online versus in person communities, which in turn impacts their local economies.

There are multiple possibilities for analyzing these themes. Bourdieu’s concept of field of struggle provides a method to analyze in-depth how the community displays or manages conflict. Or one could take Jameson’s cultural capital approach to see how it is displayed on Etsy.com. Given this perspective however, each of these analyses would boil down to how the lives of the women that use Etsy are impacted by its existence.

I suggest in the literature review that regardless of if Etsy is seen as a friend or foe of the feminist movement, it would be beneficial to take Smith and Balka's (1998) framework to look at Etsy and perform a SRIS (Sex Role Impact Statement) to determine what the impacts are. The questions asked via an SRIS would include:

Does Etsy broaden or restrict women's traditional options?

Does it increase or limit women’s chances for economic self-sufficiency?

Does it reduce or increase women's privatization in the home?

(Smith and Balka, 1988, p. 84). What are the correct answers to these questions? As technology continues to develop, its effects on gender, communities and cultures will constantly change. While the craft movement has many similar political intents to the 
turn of the century Arts and Crafts movement, there likely are similar pitfalls that would perpetuate dominant methods of control. These questions are answered in relation to the Etsy community throughout the interview responses.

The answer to the first question (Does Etsy broaden or restrict women’s traditional options?) can be seen clearly in the theme Legitimate Business. While traditional options for women historically included staying in the home, not employed or employed in low paying jobs, more recently the options are likely to include working in an office in traditional nine to five hours within the information economy. Etsy provides a venue for these women to step outside this and to own their own businesses working with their hands. Benefits of this include making one's own schedule, managing the business' budgets, providing care for children while working at home, and other qualities that are described particularly well in the Bread and Badger interview on Etsy.com. Additional incentives for this may be political, as described in the section that discusses the political intents behind owning one’s own business. These include owning the creative process and all steps behind making products, not being a part of the industrial economy and partaking in an alternative economy (such as RC trading her artwork for chiropractic services). Clearly Etsy.com does broaden women’s options in many ways.

By doing all of the above, Etsy impacts women's chances for economic selfsufficiency, the second question listed above. By helping women plug into the community online in order to exchange goods and services outside the traditional economy, it increases their chances for economic self-sufficiency, insulating them from some of the pitfalls of being a part of the traditional economy. As AG said to The Black Apple, “you’re recession-proof.” To an extent, this community exists outside the 
mainstream economy that is directly impacted by global forces such as stock markets and commodity prices. In this way too, it increases chances for economic self-sufficiency. The website and community as a whole allows them to earn an income on their own terms and on their own time, as opposed to during set business hours earning a set wage.

A major complaint all interviewees mentioned about Etsy is the low prices of items on Etsy.com. In order to be competitive among such a large amount of products, prices must be kept low, which directly impacts the women’s' incomes. This is tied to the local craft economy where each of the sellers lives. If they spend more and more time on Etsy differentiating themselves amidst a global community and selling a lower priced product, this means they are less involved in the local face-to-face economy where the market is smaller, but prices are higher and differentiation is easier. Etsy's model with economies of scale and low prices for labor reflects the industrialized impersonal market place that this community is trying to work outside of. In this way, Etsy restricts women's' chances for economic self-sufficiency.

The answer to Smith and Balka's third question: Does Etsy.com reduce or increase women's privatization in the home? varies from business owner to business owner. In many cases, Etsy.com limits women’s participation in the local economy. AF, for example, says she would sell in person if not for Etsy. By becoming less involved with the in-person community and more with the online community, the women spend more time at home on the computer, trying to differentiate themselves from among the many sellers on Etsy.com. They need to spend more time on online advertising to drive traffic from a wide audience to their online stores. This is in contrast to interacting in person when selling or buying at a local craft fair. In the case of AG however, the 
situation is reversed. There was very little in-person community where she lived, and Etsy.com plugged her into a community of crafters that she became involved with in person. The result is similar in the case of the bloggers profiled in the Local Economy section (Crimson Purl and Wise Craft). The online blog craft community led them to meet their online friends “IRL,” or in-real-life. In some cases, the online tools create connections that turn into relationships in person. This increases interactions outside the home, decreasing privatization in the home. This is the opposite of the Etsy users that NG calls Internet-heads or Etsy-people that spend all their time on their computers conducting their business on a national or international level as opposed to becoming involved in the local, in-person community. It seems that in some cases, Etsy increases privatization in the home (in the case of "Internet heads") but decreases it in other cases where individuals meet people online that they then spark an in-person relationship with.

Fiske’s description of place and space (1992) provides an interesting perspective on Etsy as a space, addressing my question "How do women use tools like Etsy.com?" Fiske describes place as an "ordered structure provided by the dominant order through which its power to organize and control is exerted” (1992, p. 160). This includes all places, like cities, universities and supermarkets. Within these places that are created by the dominant structure, Fiske says people construct spaces by their practices of living. He says space is a practiced place, and is "produced by the creativity of the people using the resources of the other” (p. 160). The women I interviewed and observed online have used these new technologies to practice place and create a space online. Within the place (Etsy) created by the dominant, their practiced lives create a space (via their crafted goods, businesses and relationships). Fiske also says that: 
The construction, occupation, and ownership of one’s own space/setting within their place/arena, the weaving of one's own richly textured life within the constraints of economic deprivation and oppression, are not just ways of controlling some of the conditions of social existence; they are also ways of constructing, and therefore exerting some control over, social identities and social relations (p. 160).

Using Etsy as a space within the constraints of oppression, the handcrafting community is able to exert control over social identities and social relations. They are able to display their social identity via their art and craft to a large community. They make a political statement by handcrafting, or "using the resources of the other" to create what they need (Fiske, 1992, p. 160). Using Etsy and other new media tools are also using resources of the other to make a political statement by owning their own business to exist outside the mainstream.

\section{Etsy.com: Recent Developments}

When I began this research in 2008, Etsy was only a couple years old, was the only website of the sort in existence, and had just hit a milestone of a following of 1 million members. The website has since continued to grow, and the community has become more and more international. There is now a Facebook.com application for Etsy shop owners to post items to their Facebook pages. Additional websites such as BigCartel.com, ArtFire.com, ishopindie.com, indiemart.com (the "mart” in this website name is particularly ironic) and many others have launched with the same purpose of Etsy.com, trying to capture a market share of the growing buying handmade trend. 
Since I conducted this research, The New York Times has continued to publish more and more articles profiling Etsy.com users. The articles however now focus more on the trials and tribulations of selling on the website, versus touting the success of whoever they are profiling. The Times seems to be catching up to its previous stance of “selling the Etsy dream.” In a December, 2009 article, the New York Times profiles artist "Ms. Gibran, who is in her 30s...had been selling her hand-knit scarves and accessories on the site for less than a year when she decided last November to quit her day job at a copy center in Atlanta. Thirteen months later, she would seem to be living the Etsy dream: running a one-woman knitwear operation, Yokoo, from her home and earning more than $\$ 140,000$ a year, more than many law associates.” The article goes on to quote Gibran: "Etsy saved my life.” But, she added, “this is the hardest job I’ve ever had” (http://www.nytimes.com/2009/12/17/fashion/17etsy.html?_r=2\&hp). It goes on to describe a near sweatshop-type scenario, however compares the hours and income Gibran makes to a law associate, an ironic mix of discourses in one article.

Regardless, it seems that has the handcrafting trend is becoming mainstream, and the mainstream media is catching on to Etsy's trajectory of growth and affiliated seller growing pains. These series of articles in The New York Times may ultimately serve as a documentary of the typical mainstreaming of a subversive political intent that loses its initial intent as it gains popularity.

Implications for future research

This study focused on a relatively small sample size of participants that live in the United States and Canada, and collected data from interviews and online content from 
websites and blogs. A study that focuses on a larger sample size of interviews could give a description of the broader implications of new media tools. Alternatively, it could also focus the data on a specific theme in more depth, i.e. how Etsy affects individuals’ income or local economy. There is also an increasingly interconnected international community that can be seen in this community. Interviewing Etsy sellers from a variety of locations around the world could provide very rich data for how Etsy is intertwined with the global economy and community. Alternatively, conducting interviews on a narrower geographical location than this study did could produce data that is more focused on local economic impacts. Conducting a textual analysis of Etsy.com and the various sections or "rooms" of the website would also provide valuable data on how individuals interact specifically on the website and how Etsy frames, drives, and forms these conversations. Another possibility would be to compare the benefits and pitfalls of using Etsy.com (which became a large organization) to those of using BuyOlympia.com, which serves the same community, but remained a small 4 person operation (as of the writing of this research).

Additionally, the availability of technology (Internet access, online conferencing tools, inexpensive design suites for individuals, and websites like Ebay, Etsy, and so on) to more users has allowed flexibility and the ability for other entrepreneurs to start a business or simply work from home for their existing employer. The benefits and pitfalls to this phenomenon are likely similar to those that affect Etsy users and the craft community. Heather B. Armstrong, the aforementioned blogger that supports her family solely from her blog, was recently invited to the White House Forum on Workplace Flexibility (documented on her blog here: http://dooce.com/2010/04/08/dc-part-two). The 
acknowledgement by the current administration of the need for a forum on this topic is indicative of discussion needed around this topic. Conducting ethnographic research on the broader topic of technology, women and work place flexibility, outside the craft community, would significantly add to the thin body of critical research on the topic of women, work and technology.

\section{Limitations}

This study took a small sample size of participants that live in various regions across the United States. They all use Etsy for different purposes, were introduced to it in different ways, and do not know each other personally - these are not the typical qualities of a traditional community. However, as I looked at how handcrafters use Etsy.com, I found that having a sample size of users that directly know each other was not imperative. They are all a part of an international new media and communication phenomenon and are rallied together by tools such as Etsy.

\section{Concluding remarks}

The answers to Smith and Balka’s (1998) questions are complicated. Etsy sellers use the website for disparate purposes, although Etsy's impact on their businesses, livelihood, and daily lives is profound. As new media and technological tools like Etsy become more pervasive and we rely on them more and more, further research on the implications of these tools will becoming increasingly important. While individual's use of these tools may have unintended consequences at the community level, tools like Etsy.com can regardless become a space for social change. 
${ }^{1}$ I mean it is kind of crazy if you're trying to get people you've never met before who don't know your work to buy your stuff. Because you have to just live on your computer which I'm not sorta, big on.....But I mean I guess Etsy has brought a lot of people to my calendar. And to my zines, maybe, who wouldn't have originally. It's so much easier than having to figure out how to build a shopping cart on your website. And then drive traffic to it. I mean I like Etsy, it's a good tool for me. And its fun to be a part of that community.

${ }^{2}$ You see A LOT of that - scrapbook prepackaged materials. And it gets annoying too because it really clogs up the system. And like the other thing that clogs up the system is their whole vintage thing. And they are like adamantly all about that. But just think of how much money they make off that that. They get $3.5 \%$ of every sale. So if all these people are throwing all this resale junk on there, it must be a huge market for them. They're not going to really like let that go. So like keep it, but maybe make another site for it, like Etsy vintage and Etsy supplies. And I'm sure people talk about it a ton in the forums. But first of all I'm modest, and also, I wouldn't want to go on the forums and start bitching about that stuff. And then get a bad name, or have the people who are making money off of it look at you like, ohh, she's like, kinda blowing a whistle, like not blowing a whistle. And it is true they are making a lot of money on that and it really isn't a fit. I think it should be three sites - supplies, vintage and art. Cuz its cool to have it, it is like a whole online super store full of cool stuff, but then its just gotten so big, that its like, each one could stand on its own. 
Works Cited

Archer Mann, S. \& Huffman, D. (2005). The decentering of second wave feminism and the rise of the third wave. Science \& Society, 69 (1), 56-91.

Balka, E. \& Smith, J. (1988). Chatting on a feminist computer network. C. Kramarae (Ed.), Technology and Women's Voices (82-97). New York: Routledge \& Kegan Paul.

Beechey, V. (1979). On patriarchy. Feminist Review, 3, 66-82.

Bickman, L \& Rog, D. (1998). Handbook of applied social research methods. Thousand Oaks: Sage Publications.

Bobel, C. (2006). Our revolution has style: contemporary menstrual product activists “doing feminism” in the third wave. Sex Roles, 54, 331-345.

Bourdieu, P. (1993). The Field of Cultural Production. Columbia University Press.

Callen, A. (1979). Women artists of the arts and crafts movement, 1870-1914. New York: Pantheon Books.

Callen, A. (1985). Sexual division of labor in the arts and crafts movement. Woman's Art Journal, 5 (2), 1-6.

Colucci, M. (2005). research shows: younger consumers spur increase in yarn projects. Retrieved March 8, 2008, from http://www.craftyarncouncil.com/know.html

Driscoll, C. (1999). Girl culture, revenge and global capitalism: cybergirls, riot grrls, spice girls. Australian Feminist Studies, 14 (29), 173-193.

Fiske, J. (1992). The Culture of Everyday Life. L. Grossberg, C. Nelson, \& P. Treichler (Eds.), Cultural Studies (154-173). New York: Routledge. 
Flew, T. (2002) New media, an introduction. New York, Oxford.

Gilley, J. (2005). Writings of the third wave: young feminists in conversation. The Alert Collector, 44(3), 187-198.

http://angrychicken.typepad.com/

http://blairpeter.typepad.com

http://blairpeter.typepad.com/weblog/2008/10/portland-i-shou.html

http://crimsonpurl.blogspot.com

http://crimsonpurl.blogspot.com/2009/06/tippy-toe-knitting.html

http://dooce.com

http://dooce.com/2010/04/08/dc-part-two

http://www.flintknits.com

http://www.flintknits.com/blog/?p=171

http://www.nytimes.com/2009/12/17/fashion/17etsy.html?_r=2\&hp

http://www.theblackapple.typepad.com/

http://spiderwomanknits.typepad.com/

http://www.yarnharlot.ca/blog/

http://Etsyaoc.ning.com

http://www.Etsy.com/storque/spotlight/quit-your-day-job-breadandbadger-3650/

Jameson, F. (1991). Postmodernism, or The Cultural Logic of Late Capitalism. Duke University Press.

Johnson, J. (1990). Selecting Ethnographic Informants. Sage Publications. 
Markowitz, S. (1994). The distinction between art and craft. Journal of Aesthetic Education, 28 (1), 55-70.

Minahan, S. \& Wolfram Cox, J. (2007). Stitch’nBitch: cyberfeminism, a third place and the new materiality. Journal of Material Culture, 12 (5), 5-21.

Maxwell, J. (2005). Qualitative Research Design: An interactive approach. Thousand Oaks: Sage Publications.

Piano, D. (2003). Resisting subjects: DIY feminism and the politics of style in subcultural production. The Post-subcultures reader (253-265). New York: Berg.

Piano, D. (2002). Congregating women: reading $3^{\text {rd }}$ wave feminist practices in subcultural production. Rhizomes, 4. Retrieved February 29, 2008 from http://www.rhizomes.net/issue4/piano.html

Pullen, M \& Matthews, S. (2006, Fall/Winter). Creating Art and Social Change in Vancouver’s Downtown Eastside. Women \& Environments International Magazine, 72/73.

Rich, E. (2005). Young women, feminist identities and neo-liberalism. Women's Studies International Forum, 28 (6), 495-508

Rosenberg, K. (2007). Needling more than the feminist consciousness [Electronic version]. The New York Times.

Silverman, D. \& Marvasti, A. (2008). Doing Qualitative Research. Sage Publications: Thousand Oaks, California.

Slovic, B. (2007). Crafty Bitches [Electronic version]. Willamette Week. Spradley, J. (1980). Participant Observation. Harcourt Brace Jovanovich College 
Publishers.

Stewart, M. (Writer). (February 29, 2008). Actress Christina Ricci [Television series episode]. In M. Stewart (Producer), The Martha Stewart Show. New York: NBC Universal.

Van Manen, M. (1990). Researching lived experience. New York: State University of New York Press.

Walker, R. (2007). Handmade 2.0 [Electronic version]. The New York Times.

Williams, A. (2009). That Hobby Looks Like A Lot of Work [Electronic Version]. The New York Times

Willis, P. (2000). The Ethnographic Imagination. Malden: Blackwell Publishers.

www.buyhandmade.org. Retrieved March 10, 2008 from http://buyhandmade.org/whybuy-handmade

www.counterfeitcrochet.org. Retrieved March, 2008 from www.counterfeitcrochet.org. www.tnna.org. Retrieved March 5, 2008 from

http://www.tnna.org/PublicMain/TheIndustry/tabid/91/Default.aspx 